\title{
Investigation on the Structural Behavior of Shear Walls with Steel Truss Coupling Beams under Seismic Loading
}

\author{
Zhiheng Deng, ${ }^{1}$ Changchun Xu, ${ }^{1,2}$ Qiang Hu, ${ }^{1,3}$ Jian Zeng, ${ }^{1,2}$ and Ping Xiang $\mathbb{D}^{4,5,6}$ \\ ${ }^{1}$ College of Civil and Architectural Engineering, Guangxi University, Nanning 530004, China \\ ${ }^{2}$ Hualan Design \& Consulting Group, Nanning 530011, China \\ ${ }^{3}$ Department of Civil and Architectural Engineering, Guangxi University of Science and Technology, Liuzhou 545006, China \\ ${ }^{4}$ School of Civil Engineering, Central South University, Changsha 410075, Hunan, China \\ ${ }^{5}$ National Engineering Laboratory for High-Speed Railway Construction, Changsha, China \\ ${ }^{6}$ Department of Architecture and Civil Engineering, City University of Hong Kong, Kowloon, Hong Kong
}

Correspondence should be addressed to Ping Xiang; pxiang2-c@my.cityu.edu.hk

Received 23 March 2017; Revised 16 October 2017; Accepted 19 October 2017; Published 25 March 2018

Academic Editor: Carlos Garcia-Mateo

Copyright $\odot 2018$ Zhiheng Deng et al. This is an open access article distributed under the Creative Commons Attribution License, which permits unrestricted use, distribution, and reproduction in any medium, provided the original work is properly cited.

Based on existing experimental results, the finite element analyses were carried out on shear wall structures with steel truss coupling beams. This work studied the seismic behaviors and the working mechanism of the steel truss coupling beam at the ultimate state and put forward two parameters: the area ratio of web member to chord and the stiffness ratio of coupling beam to shear wall. The seismic optimum design method of the coupling beam was also proposed. Afterwards, a comparative analysis was implemented on the three-dimensional shear wall model with steel truss coupling beams designed by the proposed design method. The results show that the structures designed by the proposed method have excellent seismic behaviors, the steel truss coupling beams have enough stiffness to connect shear walls effectively, and its web members have appropriate cross sections to dissipate seismic energy.

\section{Introduction}

Coupling beams (CBs) are important structural components to shear wall structures as they provide effective connections between shear wall limbs and increase global lateral stiffness. The seismic performance of shear wall structure is largely dependent on the behaviors of CBs. The steel CB has a lot of advantages such as light weight, good ductility, force clear, and easy to be replaced after the earthquake. Ever since the beginning of research on the steel CBs in the 1990s, the structural behaviors of steel CBs have been investigated by experiments and theoretical analysis [1-3]; the research pointed out that steel CB structure has sufficient rigidity, strength, toughness, and a good seismic performance; the plastic deformation of the web after yielding helps to dissipate seismic energy, thus significantly improves the seismic performance of CBs. Nonlinear seismic response of walls coupled with steel and concrete beams was also investigated [4-6]; the research demonstrated the advantages of using steel beams to couple reinforced concrete walls. Experiments and simulations have been conducted on the joints of steel CBs and shear walls [7-11], and the results demonstrated that the anchorage has important impacts on the stiffness degradation; the shear yield style steel CB has excellent ductility performance and energy performance, construction convenient, and easy maintenance and replacement, and especially the maintenance can be easily replaced after the earthquake. Wu [12] investigated the steel $\mathrm{CB}$ and concrete shear wall joints by employing experiments and finite element analysis, the failure mode of joints, strain distribution, bearing capacity, CB size, concrete strength, ductility, and hysteretic behaviors were studied.

In recent decades, composite structures [13-16] develop quickly and have been investigated in researches [17-23] and used in various kinds of structures [24-32] and infrastructures [33-42]. The steel truss CB is a special kind of steel CB that satisfies flexible layout, clear loading path, and adaptable architectural features; however, investigations on steel truss $\mathrm{CB}$ shear wall structures are scarce. Experimental researches have 


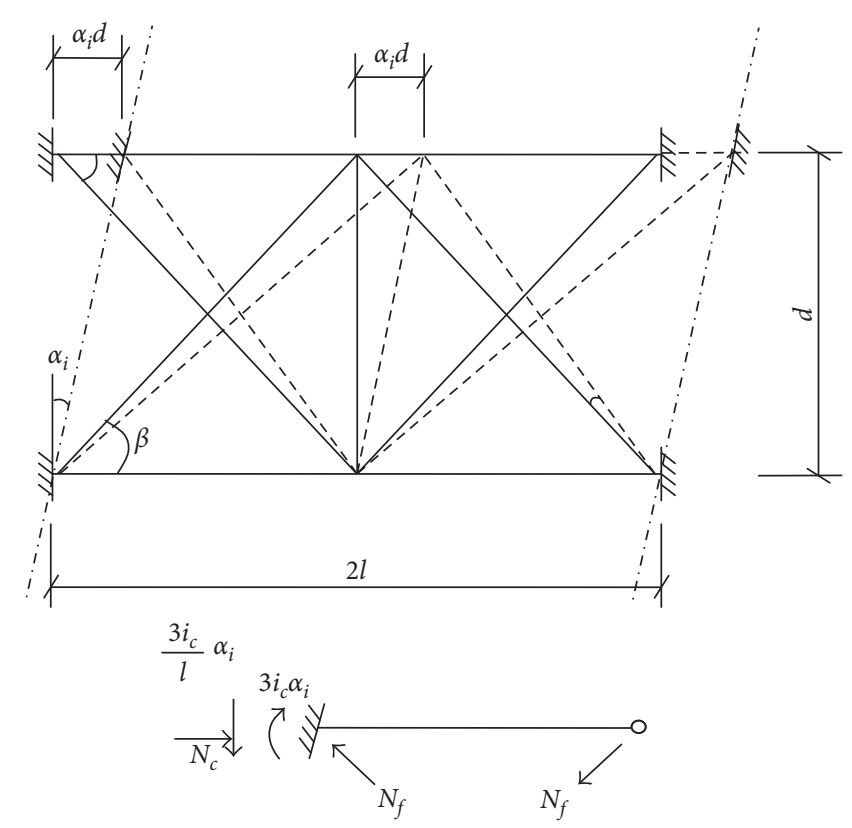

Figure 1: Deformation mode and internal force of steel truss CBs.

been employed to investigate seismic behaviors and energy dissipation mechanism of steel truss CBs under low-cyclic reversed loading [43-45]. They also proposed a novel joint design style for steel-reinforced concrete T-shaped columns, conducted experiments on joint samples under low-cyclic reversed loading [46], and further studied on hysteresis behaviors and the bond-slip curves [47]. Finite element analyses and pseudostatic tests were adopted for studies on steel truss CBs [48-50]; it is proved that the steel truss CB has excellent ductility and energy dissipation properties. They also pointed out that the appropriate design of steel truss will result in the enhancement of structural bearing capacities and the ductility; however, simply increasing the size of chord or webs may cause uncoordinated force distribution in structures. A series of works has been reported by employing cyclic and biaxial loading tests, in which the instability, fatigue strength, and hysteretic behaviors were investigated [51-55]. Condition assessment and energy dissipation of steel shear walls with tapered links under various loadings were investigated using a baseline incremental two-cycle loading protocol [56]. A rational method was proposed for determining the chord yield rotation of RC coupling beams [57], in which several recently developed coupling beam models were also reviewed. Though efforts have been made to investigate the seismic performances of steel truss CBs, further efforts on the design methods of steel truss elements, revealing the energy dissipating mechanism, stress-strain status, and how to actualize excellent mechanical performances, are still in demand.

Given the above reasons, this work presents a finite element study on the seismic behaviors of steel truss CBs; simulation results are compared with available test results. Seismic behaviors and mechanical performances under limit states are further discussed. Based on the working mechanism analysis, the area ratio of web member to chord and the stiffness ratio of coupling beam to shear wall are proposed for the evaluation of seismic performances of steel truss CBs.

This paper is structured as follows. In Section 2, the structural characteristics of the steel truss CBs are pointed out. In Section 3, the seismic behaviors and energy dissipation properties of steel truss CB shear wall structures are investigated; shear wall models, stiffness ratio, and load-displacement relationships are presented. Section 4 presents a study on the mechanism of steel truss CB structures under limit state. In Section 5, the design methods and optimization suggestion of steel truss CBs are proposed, including the evaluation of section sizes and bearing capacities. Further, Section 6 presents a threedimensional analysis of seismic performances of the steel truss CB structures; a series of parameters are adopted for the evaluation of overall seismic performances of three-dimensional steel truss CBs structures. Conclusions and discussions are drawn in Section 7.

\section{Characteristics of Steel Truss CBs}

Steel truss CBs are specific steel trusses with small spandepth ratio, which can effectively connect shear wall limbs under seismic actions, dissipate seismic energy, and reduce damage during earthquakes. The differences between the steel truss $\mathrm{CB}$ and conventional steel truss lie in the following: (1) diagonal web members can be utilized to dissipate seismic energy and (2) steel chords are presented as an effective connection between shear walls; chord members will remain in elastic stage during working without producing plastic hinges at the ends.

Taking into consideration the structural characteristics, the steel truss $\mathrm{CB}$ and steel truss will have similarities to some 


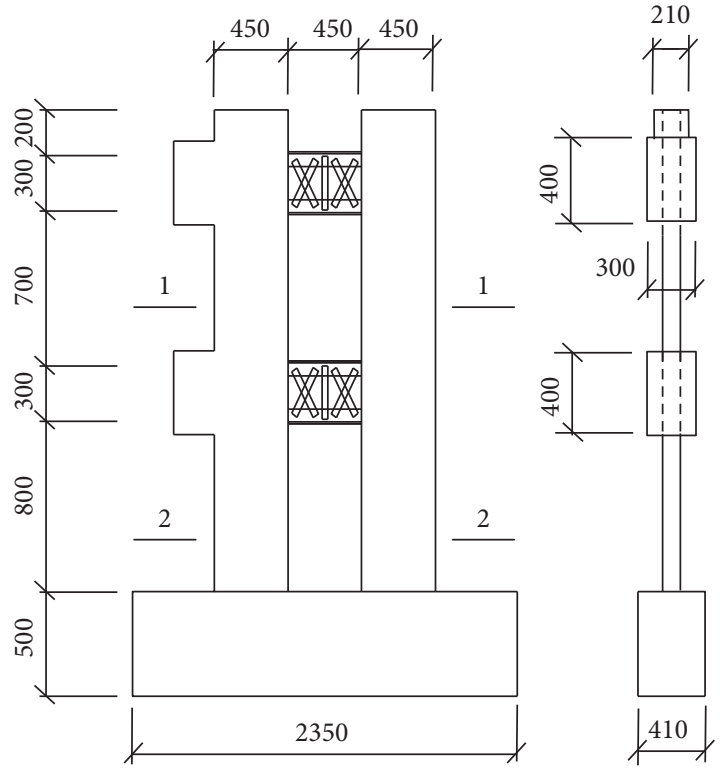

(a)

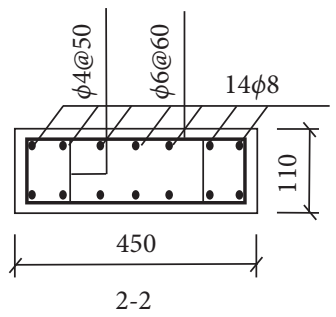

(c)

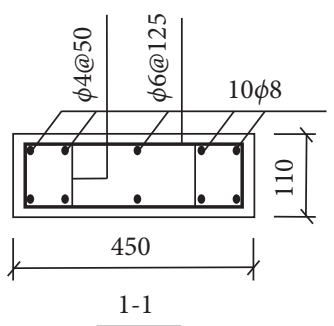

(b)

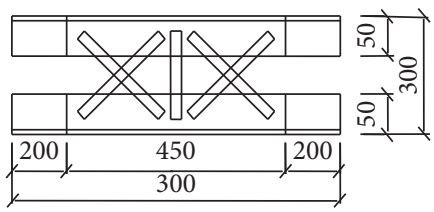

(d)

Figure 2: Shear wall specimens with steel truss CBs: (a) elevation; (b) reinforcement details of shear wall on the second floor; (c) reinforcement details of shear wall on the first floor; (d) dimensions of CBs.

extent in the working mechanism. Thus, the area ratio of web member to chord $\rho_{A}$ and the stiffness ratio of coupling beam to shear wall $\rho_{K}$ can be proposed to evaluate the mechanical and seismic performances of the steel truss CBs.

\section{Seismic Behaviors of Shear Wall Structures with Steel Truss CBs}

3.1. CB-Shear Wall Compatible Deformation and the Stiffness Ratio. The shear wall limb deforms horizontally and inclines under horizontal seismic actions. Because of the global deformation of shear wall limb, the deformation of steel truss $\mathrm{CB}$ will include rigid body motion, the rotation at the end of $\mathrm{CB}$ chords, and relative displacements of top and bottom chord members. Thus, as shown in Figure 1, it can be considered that the rotation at the ends of $\mathrm{CB}$ chords is the same as the interstorey displacement angle of the shear walls.

It is assumed that the shear force at level $i$ is $V_{i}$; the storey drift and interstorey displacement angle are, respectively, $\Delta_{i}$ and $\alpha_{i}$; the storey height, CB depth, and segment length of the $\mathrm{CB}$ are $h_{i}, d$, and $l$, respectively. The length and angle of diagonal web member are $l_{f}$ and $\beta$, respectively. As shown in Figure 1, the stretch of web member is obtained as the product of $\cos \beta$ and the relative deformation of top and bottom chords:

$$
\Delta l_{f} \approx \Delta_{i} \frac{d}{h_{i}} \cos \beta=\Delta_{i} \frac{d}{h_{i}} \frac{l}{l_{f}},
$$

then, the axial force of diagonal web member can be calculated as

$$
\sigma_{f}=E_{f} \varepsilon_{f}= \begin{cases}E_{f} \frac{\Delta l_{f}}{l_{f}}, & \varepsilon \leq \varepsilon_{y}, \\ {\left[\varepsilon_{y}+\kappa\left(\frac{\Delta l_{f}}{l_{f}}-\varepsilon_{y}\right)\right] E_{f},} & \varepsilon>\varepsilon_{y} .\end{cases}
$$

By substituting (1) into (2) and considering $\kappa=1$ when $\varepsilon \leq \varepsilon_{y}$, it can be obtained that

$$
N_{f}=E_{f} A_{f}\left[\frac{\kappa \Delta_{i} d l}{h_{i} l_{f}^{2}}+(1-\kappa) \varepsilon_{y}\right],
$$

where $E_{f}$ is the elastic modulus of web members, $\kappa$ and $\varepsilon_{y}$ are, respectively, the hardening coefficient and yield strain of the steel used for web members. 


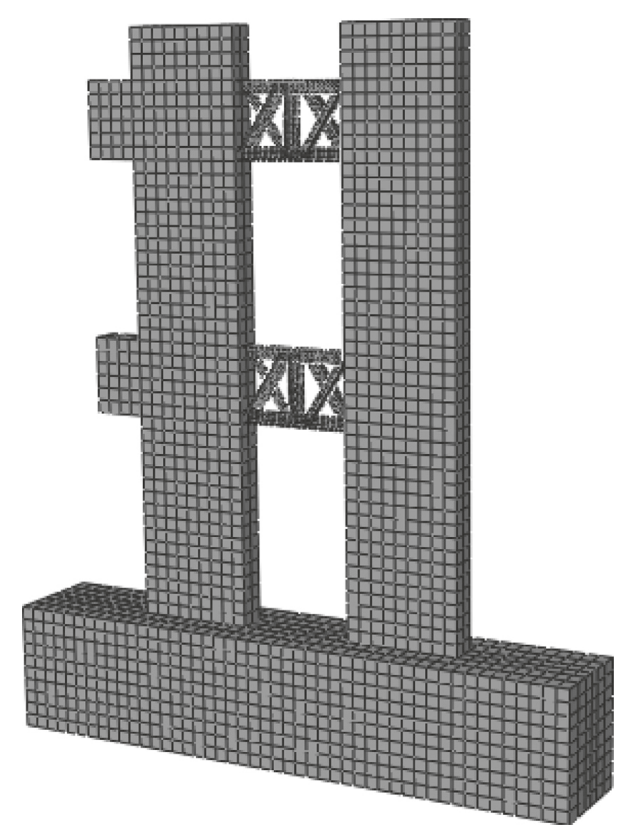

(a)

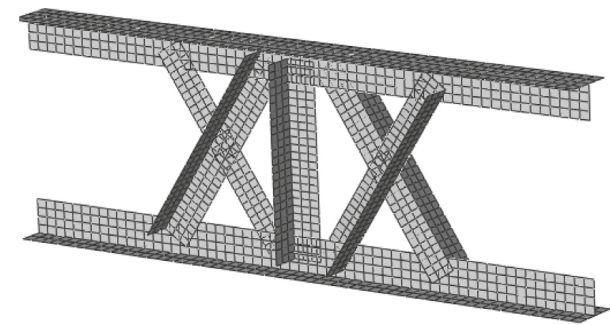

(b)

FIgURE 3: The finite element model: (a) shear wall structure; (b) CBs.

Total shear force at the CB ends is composed of vertical force component of web member and the shear forces of chords. As the shear force of chords is generated from rotation at joints, which can be considered as the interstorey displacement angle $\alpha_{i}$, the CB shear force can be expressed as

$$
V_{b}=\frac{2 \Delta_{i}}{h_{i}}\left(\psi E_{f} A_{f} \frac{\kappa d^{2} l}{l_{f}}-\frac{3 i_{c}}{l}\right)+2(1-\kappa) \psi d E_{f} A_{f} \varepsilon_{y} l_{f}
$$

where $i_{c}$ is the linear stiffness of chords calculated as $i_{c}=E_{c} I_{c} / l ; E_{c}$ and $I_{c}$ are, respectively, the elastic modulus and moment of inertia of chord section, and

$$
\psi=\frac{1}{\left(l_{f}+\Delta_{i} d l / h_{i} l_{f}\right)\left(l_{f}-\Delta_{i} d l / h_{i} l_{f}\right)} .
$$

Before the web member reaches the plastic stage, the shear stiffness of $\mathrm{CB}$ can be derived based on interstorey shear deformation as

$$
K_{b}=\left.\lim _{\Delta_{i}=0} \frac{V_{b}}{\Delta_{i}}\right|_{\kappa=1}=\frac{2}{h_{i}}\left(\frac{E_{f} A_{f} d^{2} l}{l_{f}^{3}}-\frac{3 E_{c} I_{c}}{l^{2}}\right) .
$$

The lateral stiffness of shear wall can be obtained as $K_{w}=12 E_{w} I_{w 0} / h_{i}^{3}$, where $E_{w}$ is the elastic modulus of shear wall concrete and $I_{w 0}$ is the moment of inertia of transformed concrete shear wall section, in which steel has been transformed to concrete based on equal contribution to the stiffness. Then, the stiffness ratio of shear wall to steel truss CB can be calculated as

$$
\rho_{K}=\frac{K_{b}}{K_{w}}
$$

3.2. Shear Wall Model. The finite element model of shear wall steel truss CBs, as shown in Figure 2, is built on the basis of the experimental specimens in [5], as shown in Figure 3. The elements T3D2, C3D8R, and S4R in ABAQUS are used for reinforcements, shear walls, and CBs, respectively. The stressstrain models of concrete under monotonic and cyclic loads conform to Chinese code for design of concrete structures GB 50010-2010 [58], which is determined by the characteristic value of axial compressive strength $f_{\mathrm{ck}}$ measured in the material tests. The stress-strain curve of concrete and steel is, respectively, presented in Figures 4 and 5. The material parameters of specimens are listed in Table 1.

Since specimens were loaded under pseudodynamic tests, the positive and negative skeleton curves are found not strictly symmetrical because of the certain damage existed in specimens. As shown in Figure 6, the positive skeleton curves of experiment values and modeling results match well with each other, only small discrepancy exists in the negative skeleton curve. However, the material property nonuniformity, fabrication error, and eccentricity are not considered in the finite element analysis, which may result in an overestimation of the initial stiffness in comparison with the test results. The positive hysteresis curve derived from experiments and modeling results match well with each other, as shown in Figure 7. It can be seen in Table 2 that the predicted ultimate load is considered alongside with experiments. In order to investigate the effects of $\mathrm{CB}$ size beams on the seismic performance of the structure, a series of results are obtained by changing sizes and thickness of web members, as shown in Table 3. Displacement loading is applied in the calculation, and the controlled displacement between test and analysis is different. Because the specimen was initially loaded before the low cyclic reversed loading tests and the damage displacement in the test is $28.66 \mathrm{~mm}$, we adopt a maximum displacement loading of 


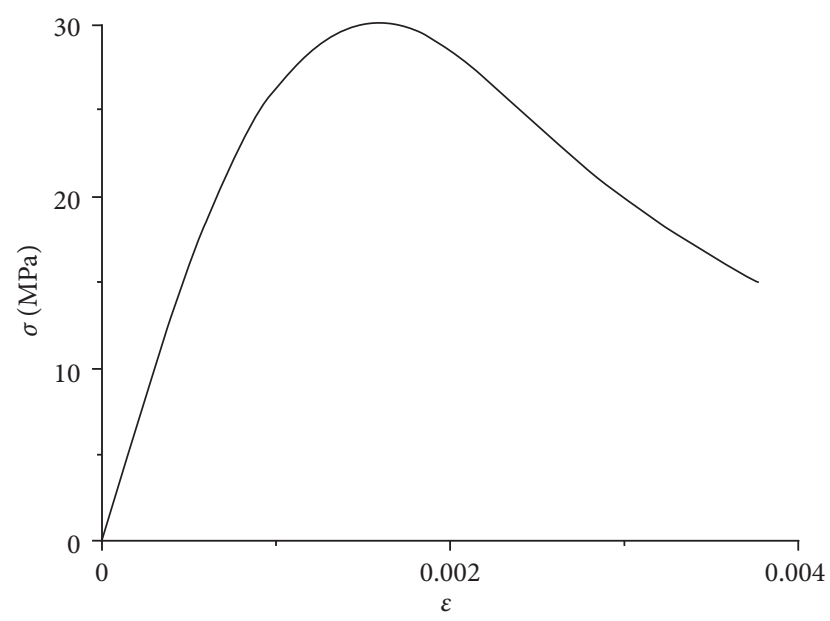

Figure 4: Concrete stress-strain curve.

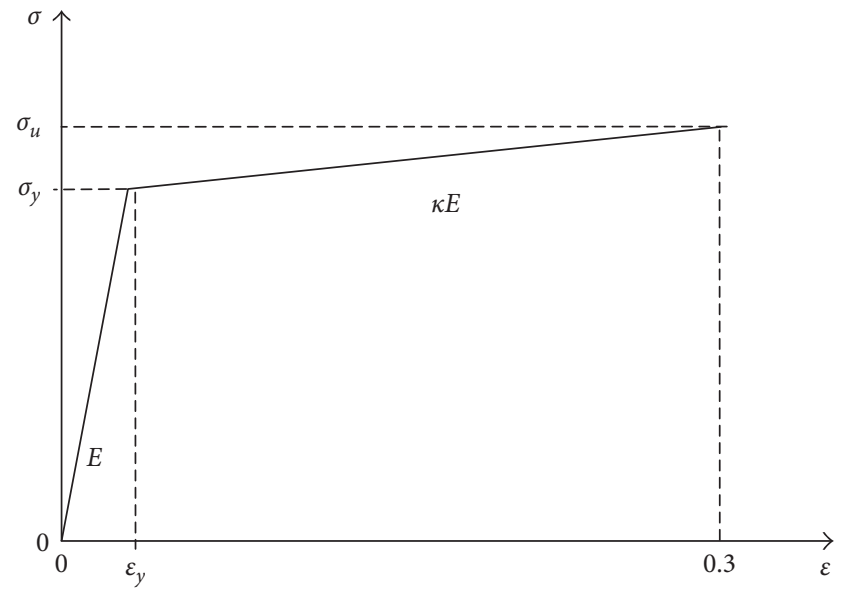

FIGURE 5: Constitutive relations of steel.

TABLE 1: Mechanical behavior of samples.

\begin{tabular}{|c|c|c|c|c|c|}
\hline Steel grade & Position & Diameter $(\mathrm{mm})$ & $\begin{array}{c}\text { Standard value of compression } \\
\text { strength }\left(\mathrm{N} / \mathrm{mm}^{2}\right)\end{array}$ & Ultimate strength $\left(\mathrm{N} / \mathrm{mm}^{2}\right)$ & Elastic modulus $\left(\mathrm{N} / \mathrm{mm}^{2}\right)$ \\
\hline HPB235 & Stirrup & 6 & 229.7 & 583.0 & $2.45 \times 10^{5}$ \\
\hline НРВ235 & Longitudinal bar & 8 & 318.1 & 457.3 & $1.86 \times 10^{5}$ \\
\hline $\mathrm{I} 10$ & Chord member & $\begin{array}{l}\text { Web } \\
\text { Flange }\end{array}$ & $\begin{array}{c}342.6 \\
307.69\end{array}$ & $\begin{array}{l}400.5 \\
387.5\end{array}$ & $\begin{array}{l}1.87 \times 10^{5} \\
1.92 \times 10^{5}\end{array}$ \\
\hline $\mathrm{L} 30 \times 3$ & Web member & - & 463.8 & 521.7 & $1.82 \times 10^{5}$ \\
\hline Concrete & Base & - & 48.98 & - & $3.45 \times 10^{4}$ \\
\hline
\end{tabular}

$30 \mathrm{~mm}$ in the simulation, which is slightly larger than the measured value $(28.66 \mathrm{~mm})$ in the tests.

3.3. Load-Displacement Curve. Several load-displacement curves of specimens are obtained and plotted in Figure 8. It can be seen that the shear force increases with the increase of web member sizes; however, the peak value of shear force decreases with the web member size increased beyond a certain degree. This goes to show that the diagonal web members and chords should have compatible sizes to ensure that all the members can cooperate well with each other and demonstrate a significant impact.

3.4. Energy Dissipation Behaviors. Reversed displacement loadings have been applied on specimens with web members of L30 angle steel; hysteretic curve is shown in Figure 9. The viscous damping coefficients $\left(h_{e}\right)$ of the specimens are presented in Table 4 and Figure 10.

As shown in Figure 9, pinching behaviors are observed in all specimens. The hysteresis curve of structure with small size web members is fatter than the structure with big web members. However, the structure with big size web members will have higher peak strength. The strength degradation is obvious for specimens with thick web members after several times of reserved loadings. That is because plastic hinges formed at the end of chords and finally result in large plastic deformation and significant stiffness degradation.

Equivalent viscous damping coefficients of specimens are calculated and plotted in Figure 10. The experimental result curve (marked with small squares) is schematically compared with a series of numerical simulation results. It can be seen that the viscous damping coefficient value is small for specimens with thin web members. With the increase of web thickness, the viscous damping coefficients decrease and tend to stabilize. Therefore, it is important to determine an appropriate CB stiffness to achieve a larger carrying capacity and good energy dissipation performance of steel truss CBs.

\section{Working Mechanism under the Limit State}

In order to study the deformation styles of steel truss CBs under limit state, the deformation of specimens can be divided into three major types as shown in Figure 11:

Type I: steel truss chords keep in elastic stage and the deformation is small; overall bending deformation occurs in diagonal web members, with $\rho_{A} \leq 0.4$ and $\rho_{K}<0.15$.

Type II: steel truss chords deform to some extent, diagonal web members buckle locally, it is likely that chord members will enter the plastic stage, but within a limited degree, with $0.4<\rho_{A} \leq 0.65$ or $0.15 \leq \rho_{K} \leq 0.2$. 


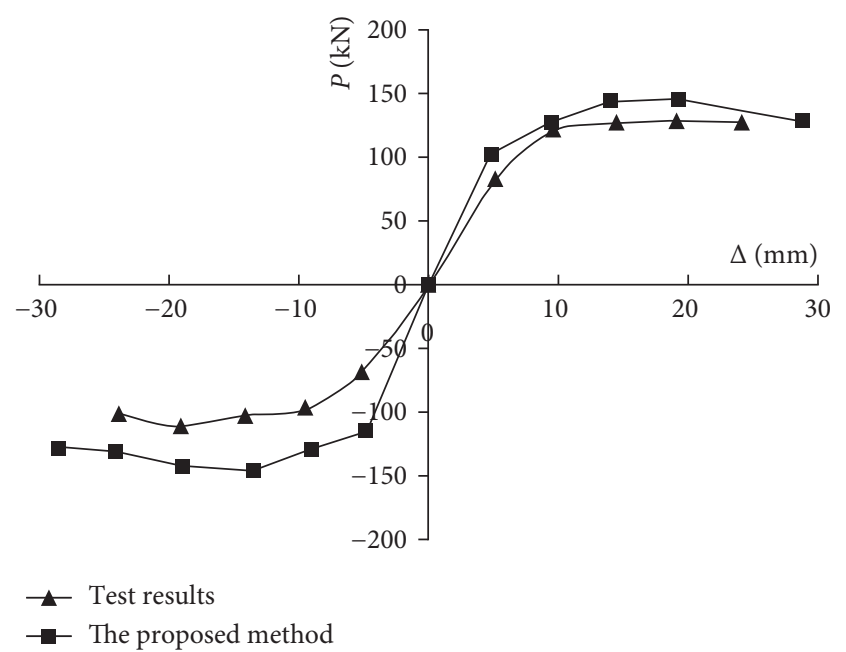

Figure 6: Skeleton curves on top floor of the specimen.

Type III: wave style buckling and plastic deformation occur on chord members wavy deformation occurs, enter more plasticity, however, diagonal web members remain straight without bending deformation, with $\rho_{A}>0.65$ and $\rho_{K}>0.2$.

In the deformation type I, deformation of $\mathrm{CB}$ chord is small, chord members are in elastic stage; globally bending deformation occurs on diagonal web members. In the deformation type II, CB chord members deform to elastoplastic state; local buckling occurs on diagonal web members, which will have certain impact on the energy dissipation performances of steel truss CBs. In the deformation type III, the deformation of web members is small because of the big sizes of web members; however, large plastic deformation occurs on chords. In this case, seismic energy is majorly dissipated by the plastic deformation and plastic hinges occurred on chord members, which may result in a decrease of bearing capacity of steel truss CBs. The connection between shear wall limbs will also be reduced. Therefore, the deformation types I and II can satisfy the requirement of steel truss CBs; however, the deformation characteristics and energy dissipation performances of the type III are not satisfactory.

Taking into consideration the bearing capacity and energy dissipation performance analysis results, the reasonable area ratio and stiffness ratio of steel truss $\mathrm{CBs}$ can be obtained as the threshold value between the deformation types I and II, namely:

$$
\begin{aligned}
& \rho_{A}=0.4, \\
& \rho_{K}=0.15 .
\end{aligned}
$$

In order to ensure that the steel CBs will deform as the style I and II, it is suggested that the area ratio and stiffness ratio of steel truss CBs should not exceed 0.5.

\section{Seismic Design Optimization of Steel Truss CBs}

The main function of steel truss CBs lies in an effective connection between shear wall limbs and energy dissipation

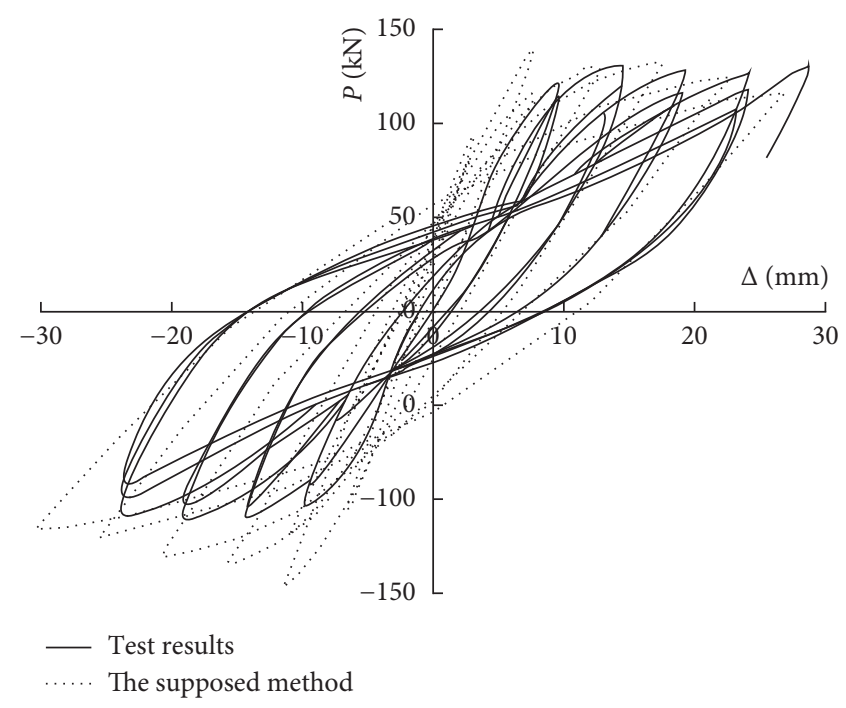

FIgURE 7: Hysteretic curves on top floor of the specimen.

TABLE 2: Comparison of the calculation results.

\begin{tabular}{lccccc}
\hline \multicolumn{3}{c}{ Yield load $P_{y}(\mathrm{kN})$} & \multicolumn{3}{c}{ Ultimate load $P_{u}(\mathrm{kN})$} \\
Test value & FEM & Error (\%) & Test value & FEM & Error (\%) \\
\hline 69.44 & 63.36 & 8.75 & 116.18 & 115.58 & 0.52 \\
\hline
\end{tabular}

\begin{tabular}{|c|c|c|c|c|}
\hline \multirow[t]{2}{*}{ Span (m) } & \multirow[t]{2}{*}{ Depth (m) } & \multirow{2}{*}{$\begin{array}{l}\text { Chord member } \\
\text { size }(\mathrm{mm})\end{array}$} & \multicolumn{2}{|c|}{$\begin{array}{l}\text { Web angle steel } \\
\text { properties }(\mathrm{mm})\end{array}$} \\
\hline & & & Limb width & Thickness \\
\hline 0.45 & 0.3 & Half-I10 & 30 & $3-7$ \\
\hline 0.45 & 0.3 & Half-I10 & 40 & $3-5$ \\
\hline 0.45 & 0.3 & Half-I10 & 45 & $4-6$ \\
\hline 0.45 & 0.3 & Half-I10 & 50 & $4-6$ \\
\hline 0.45 & 0.3 & Half-I10 & 56 & $4,5,8$ \\
\hline 0.45 & 0.3 & Half-I10 & 63 & $4-6,8,10$ \\
\hline
\end{tabular}

TABle 3: Specimens details.

under seismic actions through the plastic deformation of CB web members. Since the CB web member will definitely reach plastic deformation stage under heavy seismic actions, no specific provision could be found related to this situation. Therefore, it is not practical to design the steel truss CBs based on the ultimate limit state design method specified in current codes code of practice for building design. This research proposes steel truss CB design methods based on the foregoing characteristics. The proposed design method is to achieve certain seismic performances by appropriately designed stiffness ratio and area ratio of steel truss CBs. Specifically, reasonable designed area ratio will be used to ensure energy dissipation performances of web members, and the stiffness ratio will be utilized to provide an effective connection between shear wall limbs. 


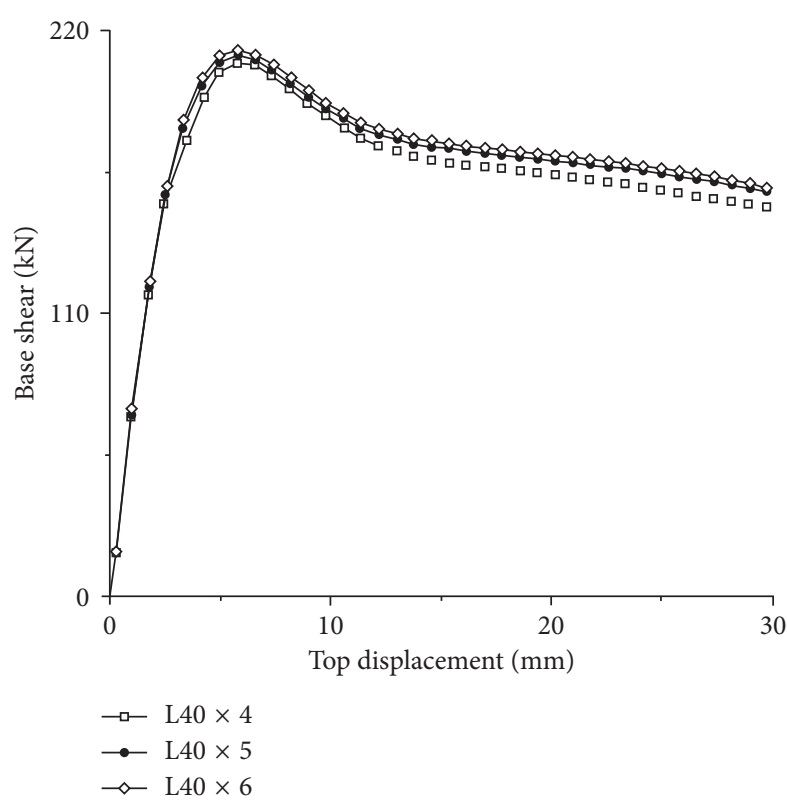

(a)

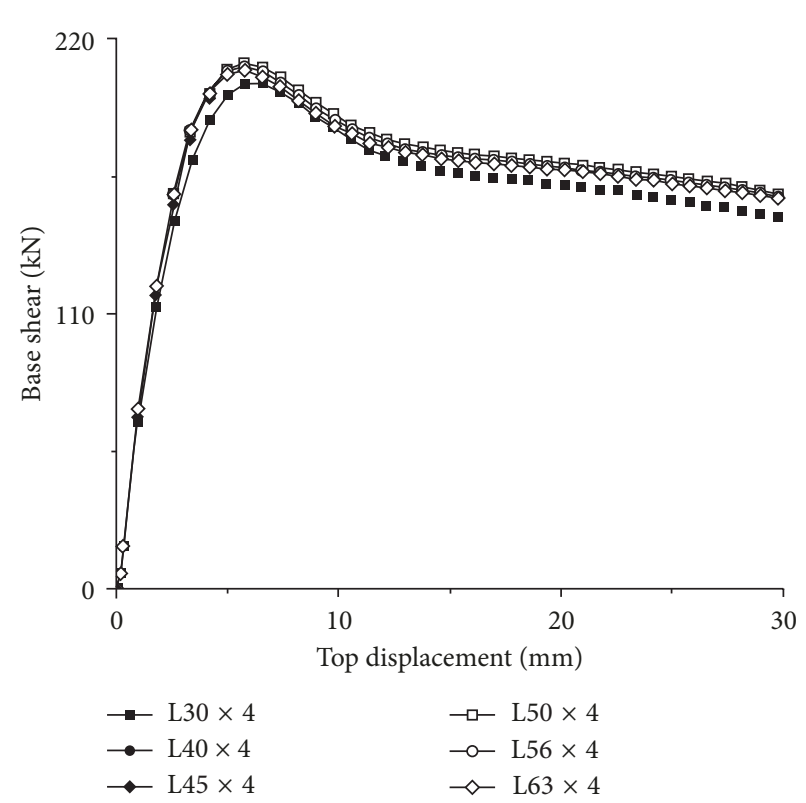

(b)

FIGURE 8: Base shear-displacement curves of the specimen.

5.1. Estimation of Cross-Section Dimensions. The effective length of chord member under compression is defined as $l_{x 0}=l$, and allowable slenderness ratio is $\lambda$. By defining $i_{x}=$ $l_{x 0} /[\lambda]$ and then $I_{c}=i_{x}^{2} A_{c}=l^{2} A_{c} /[\lambda]^{2}$, substituting into (6), it has

$$
K_{b}=\frac{2 A_{f}}{h_{i}}\left(\frac{E_{f} l d^{2}}{l_{f}^{3}}+\frac{3 E_{c}}{\rho_{A}[\lambda]^{2}}\right) .
$$

By substituting $\rho_{A}=A_{f} / A_{c}$ and (9) into (7), the crosssectional area of web member can be estimated as

$$
A_{f}=\frac{\rho_{K} h_{i}}{2\left(E_{f} l d^{2} / l_{f}^{3}+3 E_{c} / \rho_{A}[\lambda]^{2}\right)} K_{w} .
$$

5.2. Calculation of Bearing Capacity. The bearing capacity of the steel truss $\mathrm{CB}$ is evaluated by considering two cases:

(1) Under small earthquakes, diagonal web members yield and the steel truss CBs reach the bearing capacity, then interstorey displacement can be calculated as

$$
\Delta_{\text {iy }}^{N}=\frac{h_{i} l_{f}}{d l} \frac{f_{y}}{E_{f}} .
$$

At this time, diagonal web members reach buckling forces; therefore, the carrying capacities provided by web members under tension are only considered. Then, the bearing capacity of steel truss CBs can be obtained by considering $\kappa=1$ and substituting (11) into (4), which is expressed as

$$
V_{\mathrm{bu}}^{N}=\frac{2 l_{f}^{2} f_{y}}{d l E_{f}}\left(\psi E_{f} A_{f} \frac{d^{2} l}{l_{f}}-\frac{3 i_{c}}{l}\right)
$$

where $\psi=1 /\left(l_{f}+l_{f} f_{y} / E_{f}\right)\left(l_{f}-l_{f} f_{y} / E_{f}\right)$.

(2) Under heavy earthquakes, in order to avoid shear failure of steel truss CBs, the bearing capacity can be calculated when the chord member yields. At this time, the interstorey displacement is

$$
\Delta_{\mathrm{iu}}^{V}=\frac{t_{w} l^{2} h_{i}}{3 E_{c} S_{c}} f_{v}
$$

By substituting (13) into (4) and considering the buckling of diagonal web members under compressive force, the shear capacity of steel truss CBs can be derived as

$V_{\mathrm{bu}}=\frac{2 I_{c} t_{w}}{S_{c}} f_{v}\left(\psi \frac{\kappa E_{f} A_{f} d^{2} l^{3}}{3 l_{f} E_{c} I_{c}}-1\right)+2 \psi_{1}(1-\kappa) d E_{f} A_{f} \varepsilon_{y} f_{y}$,

where $\psi_{1}=1 /\left(l_{f}+d t_{w} l^{3} / 3 l_{f} E_{c} S_{c} f_{v}\right)\left(l_{f}-d t_{w} l^{3} / 3 l_{f} E_{c} S_{c} f_{v}\right)$ and $f_{v}$ is the shear yield strength of steel used for chord members.

Table 4 shows the bearing capacity at CB ends by considering the proposed two cases. It can be seen that the shear capacities derived from modeling results are in good agreement with experimental values in the case. It means that the proposed design method is effective for the case under small earthquakes. However, for the case under heavy earthquakes, discrepancies exist between finite element modeling results and the simulation results derived based on the proposed methods. That is because the proposed method does not consider the plasticity of chord members. Though 


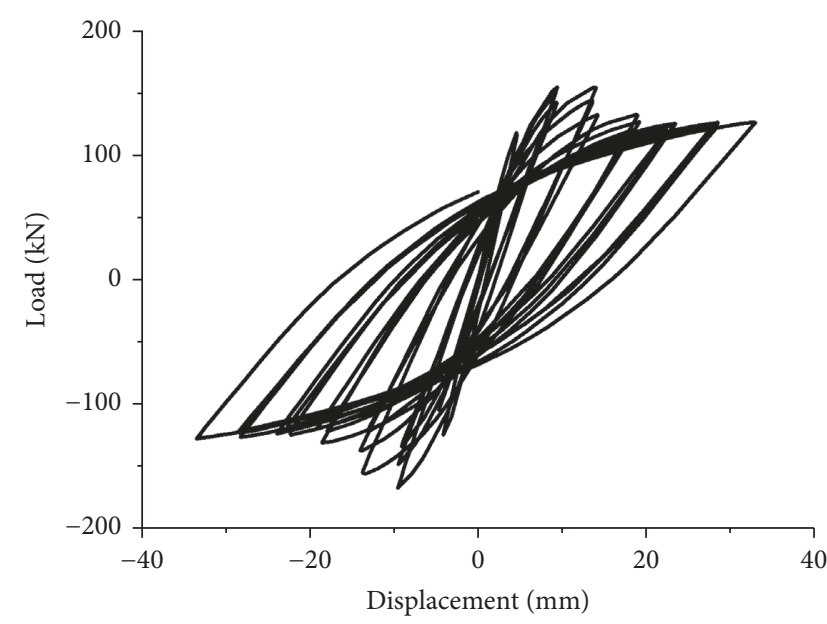

(a)

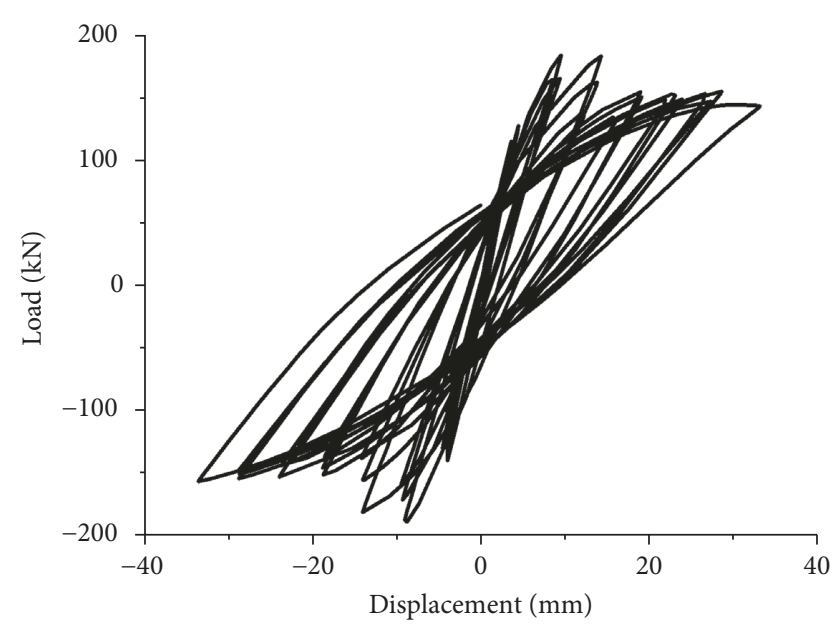

(b)

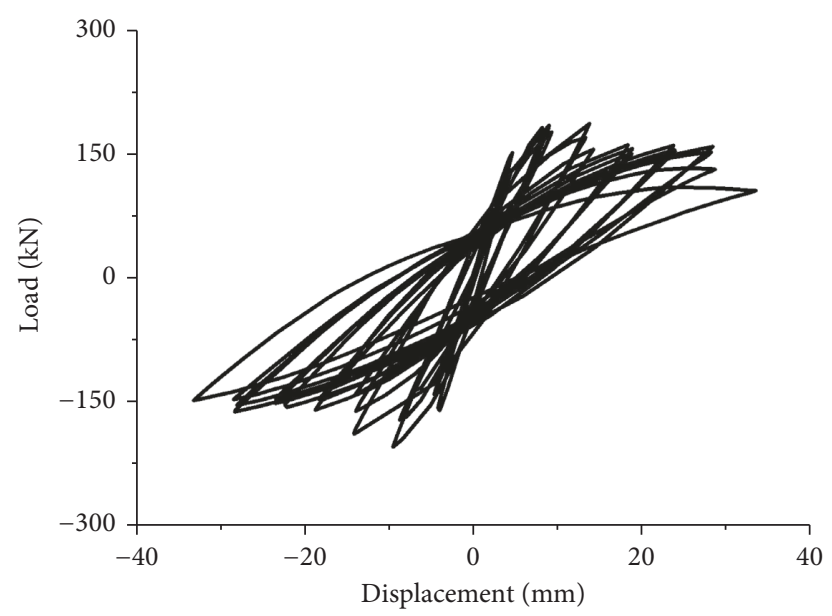

(c)

Figure 9: Load-displacement hysteresis curves of specimens: (a) L30 $\times 3$; (b) L30 $\times 5$; (c) L30 $\times 7$.

TABLE 4: Bearing capacities of the specimens.

\begin{tabular}{|c|c|c|c|c|c|c|}
\hline \multirow{2}{*}{ Diagonal web member style } & \multicolumn{3}{|c|}{ Case 1: diagonal web member yielding } & \multicolumn{3}{|c|}{ Case 2: ultimate state } \\
\hline & Test value & Result from this work & FEM & Test value & Result from this work & FEM \\
\hline $\mathrm{L} 30 \times 3$ & 69.44 & 68.79 & 63.36 & 116.18 & 97.28 & 115.58 \\
\hline $\mathrm{L} 30 \times 4$ & - & 87.33 & 95.78 & - & 115.67 & 101.43 \\
\hline $\mathrm{L} 40 \times 3$ & - & 89.78 & 84.96 & - & 118.10 & 104.47 \\
\hline $\mathrm{L} 40 \times 4$ & - & 115.31 & 115.11 & - & 143.43 & 142.87 \\
\hline $\mathrm{L} 40 \times 5$ & - & 140.15 & 137.46 & - & 168.06 & 159.93 \\
\hline
\end{tabular}

small discrepancies are found in values of the predicted bearing capacities, the impact is limited and the deformation model and intrinsic working mechanism are fully unveiled.

\section{Three-Dimensional Seismic Performance Analyses of Shear Walls}

6.1. Model Establishment. In order to study the threedimensional behaviors of the steel truss CBs and shear wall limbs, a six-storey three-dimensional shear wall model with steel truss CBs is established for numerical studies, as shown in Figures 12 and 13. Details of the specimens are presented in Table 5. Displacement loading, with the maximum displacement value of $0.3 \mathrm{~m}$, is applied at the top level.

6.2. Carrying Capacity. Bottom shear force versus top displacement $(F v-\Delta)$ curves are presented in Figure 14. It is found that the three $F v-\Delta$ curves shown in Figure 14 are quite different. The initial stiffnesses of the three specimens are almost the same. However, it can be seen that as the area 


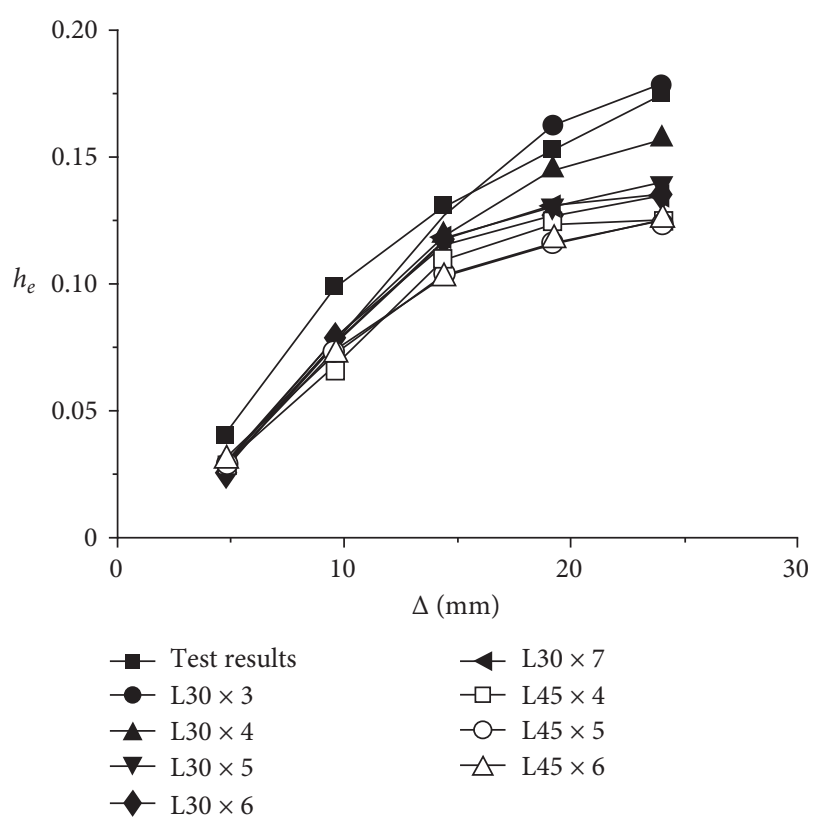

FIGURE 10: Equivalent viscous damping coefficient, $h_{e}$.

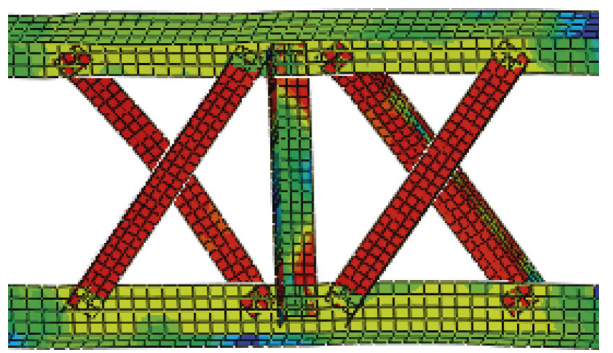

(a)

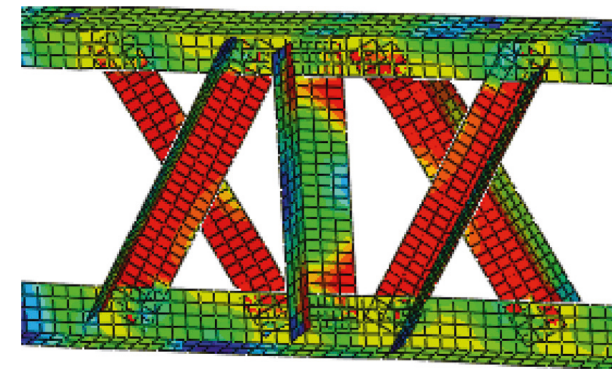

(b)

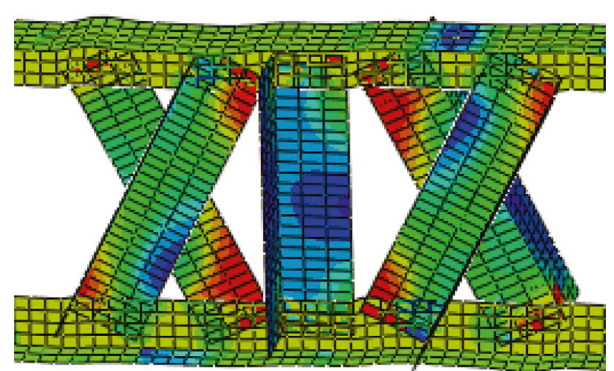

(c)

FIGURE 11: Deformation modes of the coupling beams: (a) type I: $\rho_{A} \leq 0.4$ and $\rho_{K}<0.15$; (b) type II: $0.4<\rho_{A} \leq 0.65$ or $0.15<\rho_{K}<0.2$; (c) type III: $\rho_{A}>0.65$ and $\rho_{K}>0.2$.

ratio and stiffness ratio increase, the initial stiffness of the curve increases slightly. The stiffness ratio and area ratio of specimen WALL1 are small, and the yield load and peak load are relatively lower than those of the other two specimens. This is due to that the area ratio and stiffness ratio are relatively small and the stiffness of the CB is also small. Thus, the constraints of the shear wall are weak, and the horizontal load is mainly taken by the shear wall. Consequently, the bearing capacity reaches the peak load quickly. With the increase of the stiffness ratio and area ratio, the stiffness and the peak load of specimen WALL2 are also increased. Meanwhile, the area ratio is close to the reasonable value, and the CB provides enough restraint on the shear wall. The horizontal load is supported by the combined effect of the $\mathrm{CB}$ and the shear wall, so the bearing capacity is high and the ductility is also good. The stiffness ratio and area ratio of 

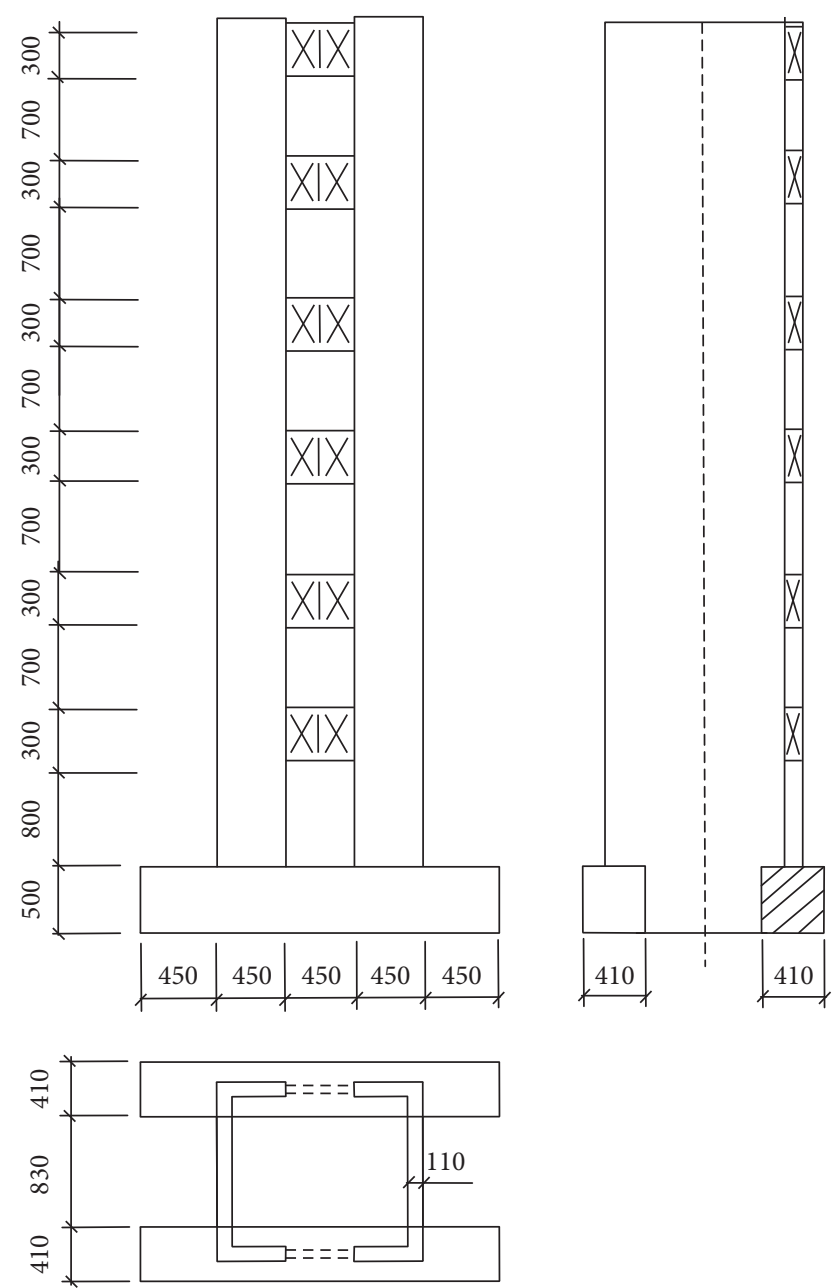

FIGURE 12: Multilevel shear wall model with steel truss coupling beam.

the specimen WALL3 are even larger, which result in the highest peak load among the three specimens. At this time, the constraint of the $\mathrm{CB}$ on the shear wall is obviously increased, and it seems that the bearing capacity of the shear wall structure can be increased. However, plastic deformation develops at the end of the chord due to the large area ratio, and the plastic hinge will finally weaken the constraints of the shear wall. Therefore, the loading capacity decreased rapidly, and the bearing capacity degradations are more significant than those of WALL1 and WALL2.

6.3. Energy Dissipation Behaviors. In order to evaluate the energy dissipation behaviors of the steel truss CB structure, bottom shear force versus top displacement hysteresis curves are plotted in Figure 15. It can be seen from the three plots that the hysteresis curve is relatively fat for the specimen WALL1 with small stiffness ratio and area ratio. The hysteresis curves are getting thinner with the increase of the stiffness ratio and area ratio, which means the energy dissipation capacities are decreasing. High stiffness ratio and area ratio will definitely result in a significantly dropped energy dissipation performance.

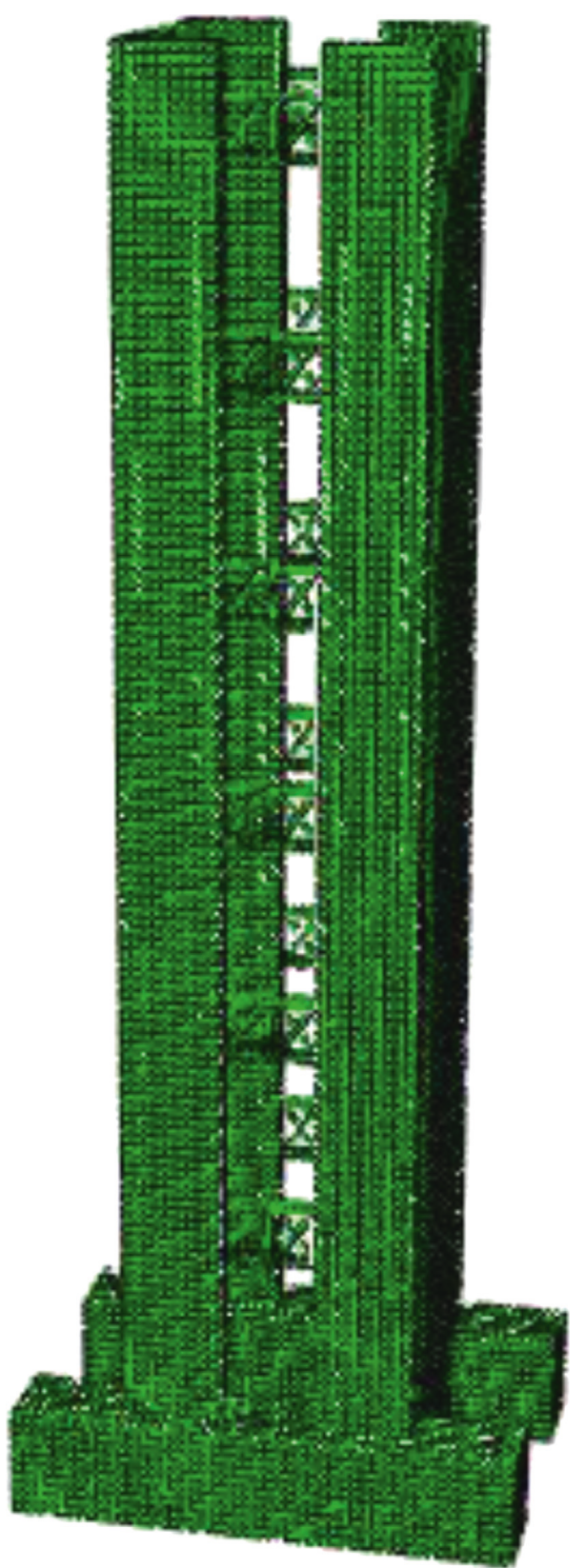

FIGURE 13: Multilevel three-dimensional finite element shear wall model with steel truss CBs.

TABLE 5: Specimen details of steel truss CB shear wall structure.

\begin{tabular}{lcccc}
\hline Specimen & $\begin{array}{c}\text { Chord member } \\
\text { type }\end{array}$ & $\begin{array}{c}\text { Web member } \\
\text { type }\end{array}$ & $\begin{array}{c}\text { Area } \\
\text { ratio }\end{array}$ & $\begin{array}{c}\text { Stiffness } \\
\text { ratio }\end{array}$ \\
\hline WALL1 & Half-I10 & L30 $\times 3$ & 0.2448 & 0.0765 \\
WALL2 & Half-I10 & L40 $\times 4$ & 0.4321 & 0.1435 \\
WALL3 & Half-I10 & L56 $\times 5$ & 0.758 & 0.26 \\
\hline
\end{tabular}

Equivalent viscous damping coefficients are calculated and presented in Figure 16. It is analyzed that (1) the viscous damping coefficient of specimen WALL1 increases with the increase of displacement load. Because the web member is 


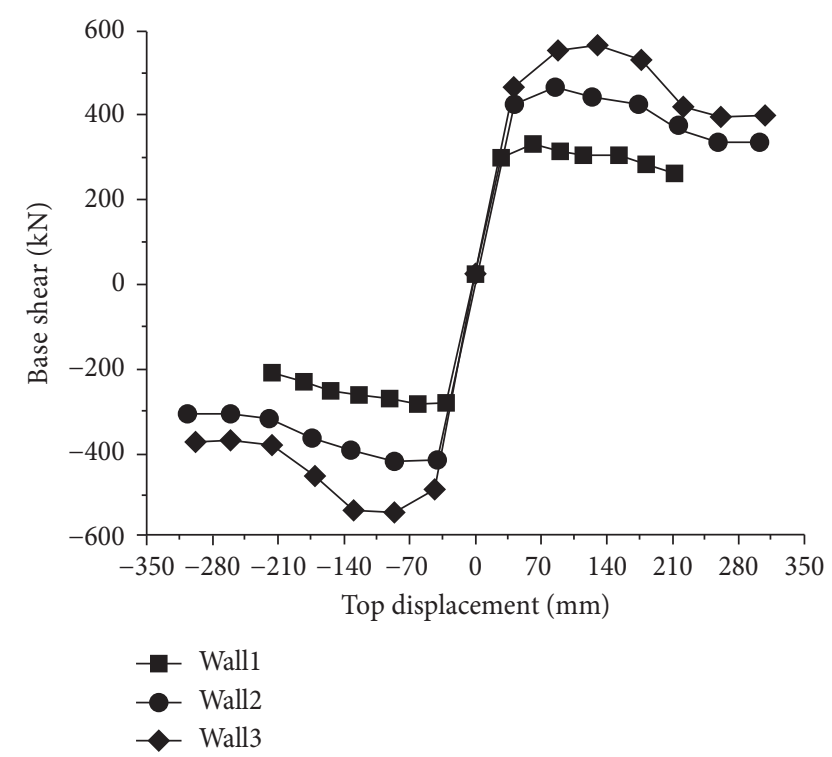

Figure 14: Base shear force-top displacement curves of the specimens.

relatively small in the specimen WALL1, diagonal web members can participate in energy dissipation and gradually take major role in dissipating seismic energy. Thus, the viscous damping coefficient is always increasing with the increase of the displacement load, but the peak value is small; (2) the viscous damping coefficient curves of the specimens WALL2 and WALL3 could be generally divided into three segments with specific characteristics in each segment. The three segments are, respectively, upward, descent, and peak; (3) the viscous damping coefficient curve and peak value of the specimen WALL2 are the highest among the three specimens. Because the web member size is relatively large, the web members play a major role in the energy dissipation during reversed loading procedure. Thus, the viscous damping coefficient increases with the increase of displacement load. However, the viscous damping coefficient decreases in the last stage because of the yielding and plastic deformation of web members; (4) the web member size of the specimen WALL4 is the largest; therefore, the deformation of web members is very small; the web will not participate effectively in the energy dissipation under seismic actions. In this case, the seismic energy is dissipated only by the plastic deformation of chord members. Thus, the viscous damping coefficients of WALL3 are small; peak value occurs in an early stage. Furthermore, the viscous damping coefficients decrease significantly in the last loading stage because of the failure of chord members.

6.4. Deformation Characteristics. Judging from the deformation and stress states of the concrete shear wall limbs and steel truss CBs, the deformation and stress are large in the lower storey and relatively small in the upper storey. In order to investigate the failure deformation and characteristics, the shear wall deformation and Mises stress

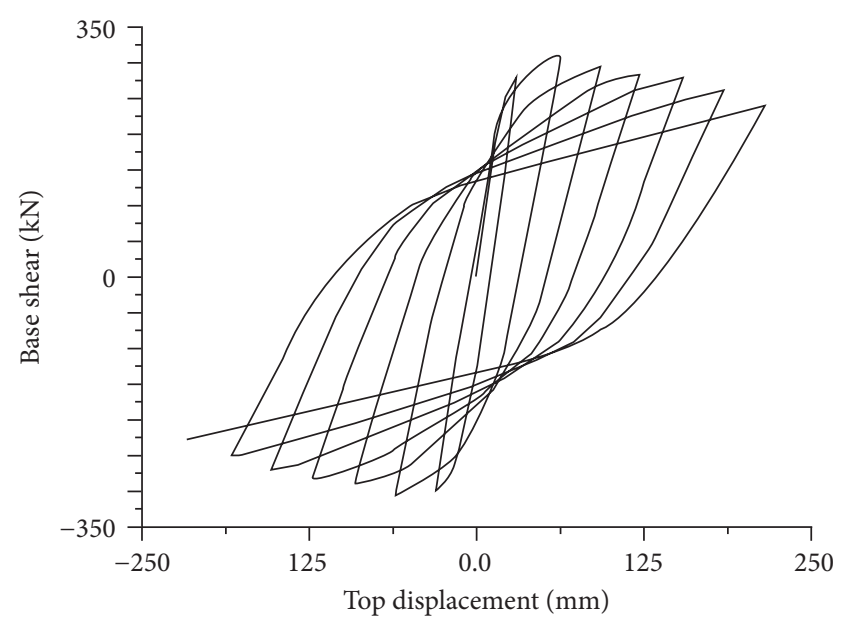

(a)

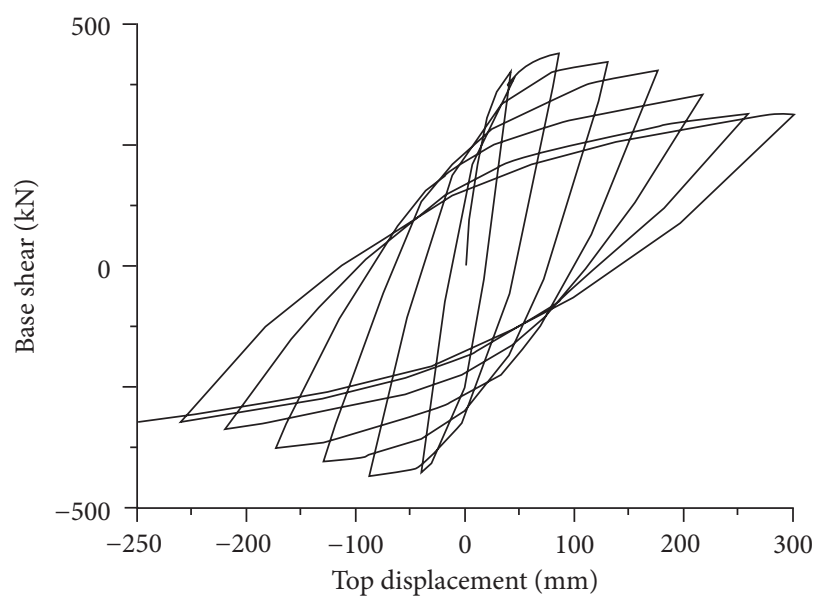

(b)

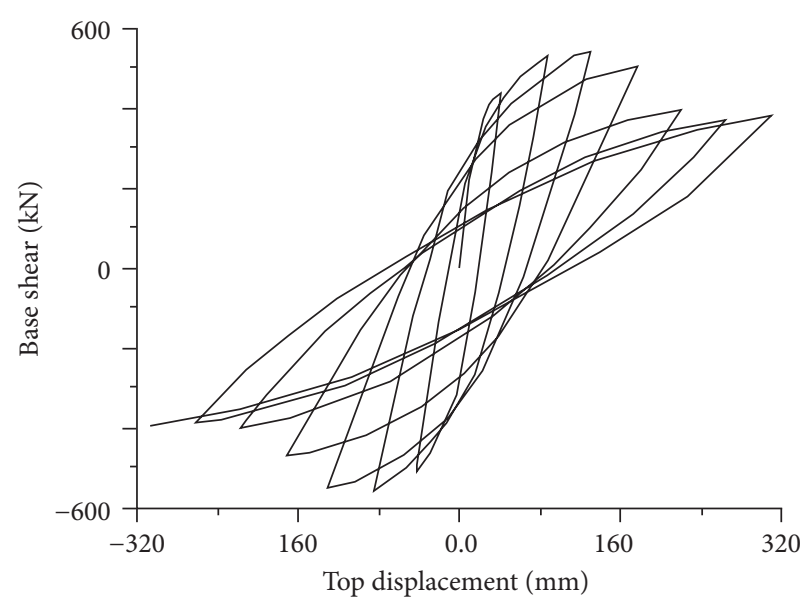

(c)

FIgURE 15: Hysteretic curves of bottom shear force versus top displacement: (a) WALL1; (b) WALL2; (c) WALL3.

obtained under the largest deformation load are presented in Figure 17. The deformed shapes of shear wall limb of the three specimens are comparable. Generally, the stresses in shear wall limbs increase with the increase of the area ratio 


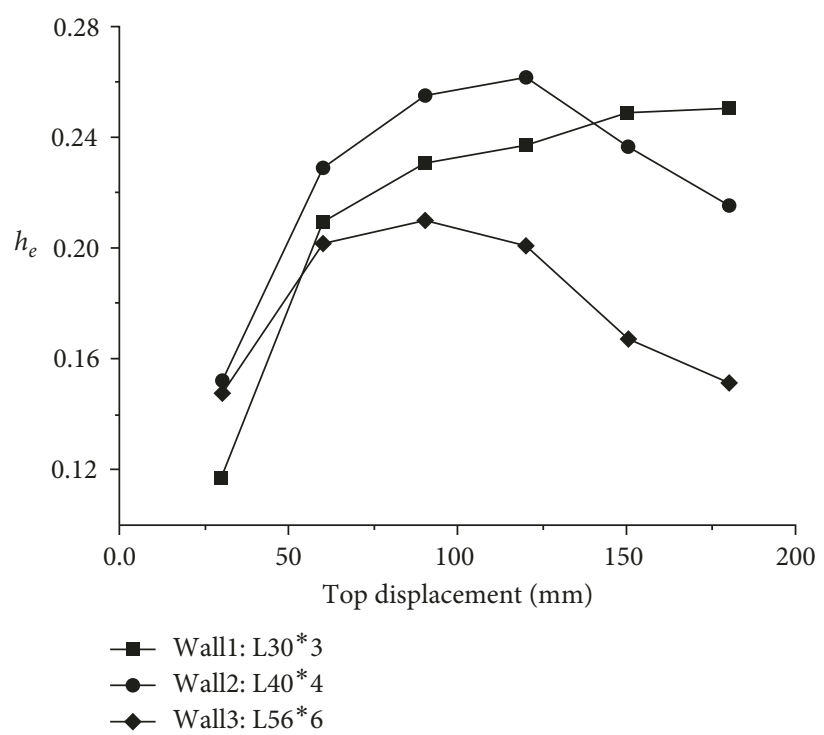

Figure 16: Equivalent viscous damping coefficient, $h_{e}$.

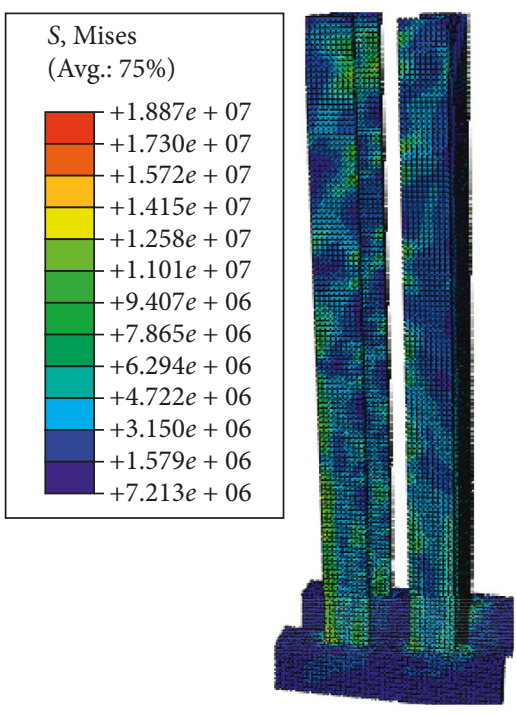

(a)

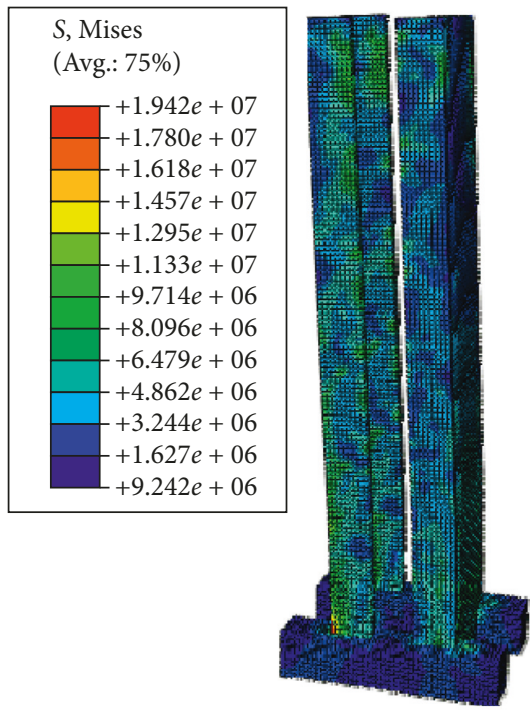

(b)

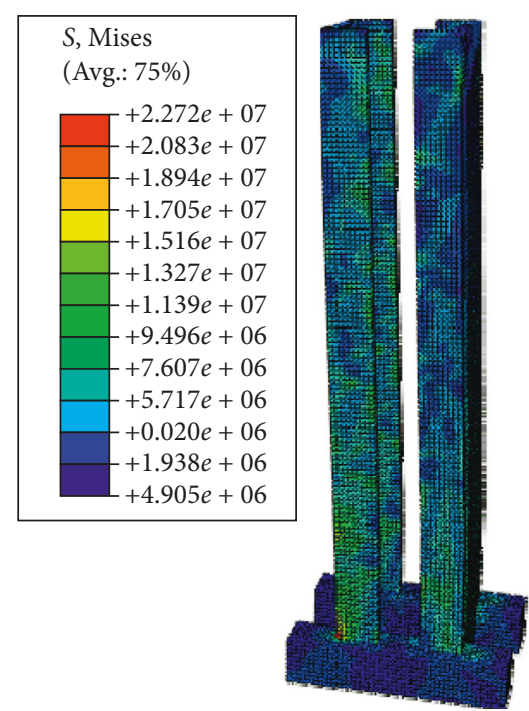

(c)

FIGURe 17: Deformation and Mises stress (unit: N/m²) of the shear walls: (a) specimen WALL1; (b) specimen WALL2; (c) specimen WALL3.

and stiffness ratio, especially the shear wall stress state of the specimen WALL1 is comparable to the stress state in the shear wall of the specimen WALL2. However, the stress state of the specimen WALL3 is even larger, which demonstrates that the steel truss CBs in WALL1 and WALL2 can effectively dissipate seismic energy and thereby help to reduce the damage to shear wall limbs.

The deformation shape and Mises stress state of steel truss CBs under the largest displacement load are presented in Figure 18. It is found that the deformation model of all three specimens has common characteristics. The specimens WALL1 and WALL2 deform globally as an integral, the deformations of web members are majorly torsion. However, wavy deformation style and plastic deformation occurs in the specimen WALL3 because of the large stiffness of diagonal web members. The peak Mises stress in the specimen WALL2 is the smallest among all three specimens; the whole web section of the specimen WALL2 is completely yielding in compression, the stress distributes evenly along the whole cross section. Though the diagonal web members of the other two specimens are also developed to plastic stage, the stress distributions in the cross section are inhomogeneous, and stress concentration occurs at the end of web members.

From the above analysis, it is understood that the stiffness ratio and area ratio of steel truss CBs have a significant impact on the shear wall rigidities, energy dissipation properties, stress distribution, and deformation 


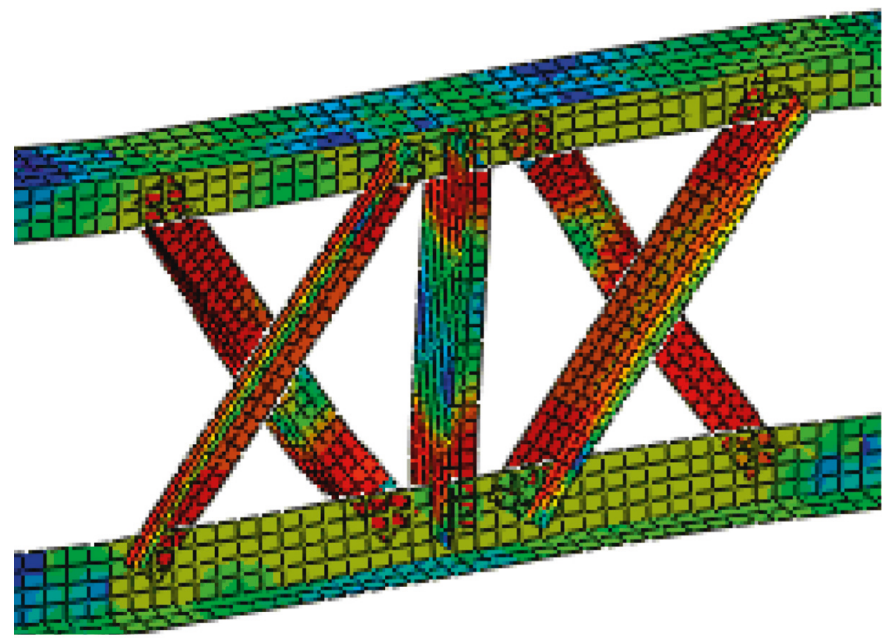

$S$, Mises

SNEG (fraction $=-1.0$ ) (Avg.: $75 \%$ )

\begin{tabular}{|l}
$+4.924 e+08$ \\
$+4.924 e+08$ \\
$+4.130 e+08$ \\
$+3.733 e+08$ \\
$+3.336 e+08$ \\
$+2.939 e+08$ \\
+ \\
$+2.542 e+08$ \\
$+2.145 e+08$ \\
$+1.748 e+08$ \\
$+1.350 e+08$ \\
$+9.534 e+07$ \\
$+5.563 e+07$ \\
$+1.592 e+07$
\end{tabular}

(a)

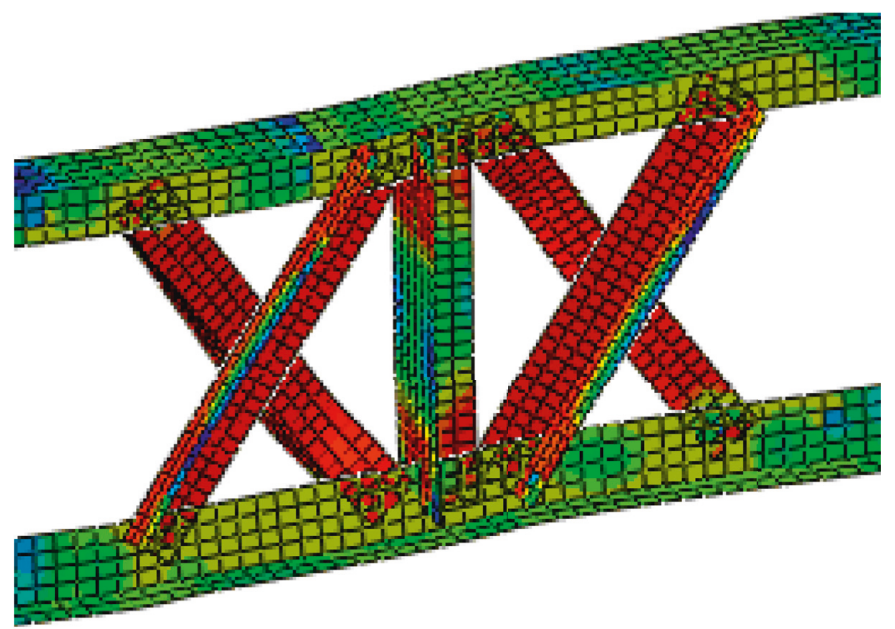

S, Mises

SNEG $($ fraction $=-1.0)$ (Avg.: $75 \%$ )

$+4.694 e+08$ $+4.312 e+08$ $+3.929 e+08$

$+3.547 e+08$

$+3.165 e+08$ $+2.783 e+08$ $+2.400 e+08$ $+2.018 e+08$ $+1.636 e+08$ $+1.254 e+08$ $+8.713 e+07$ $-4.890 e+07$ $+1.068 e+07$

(b)

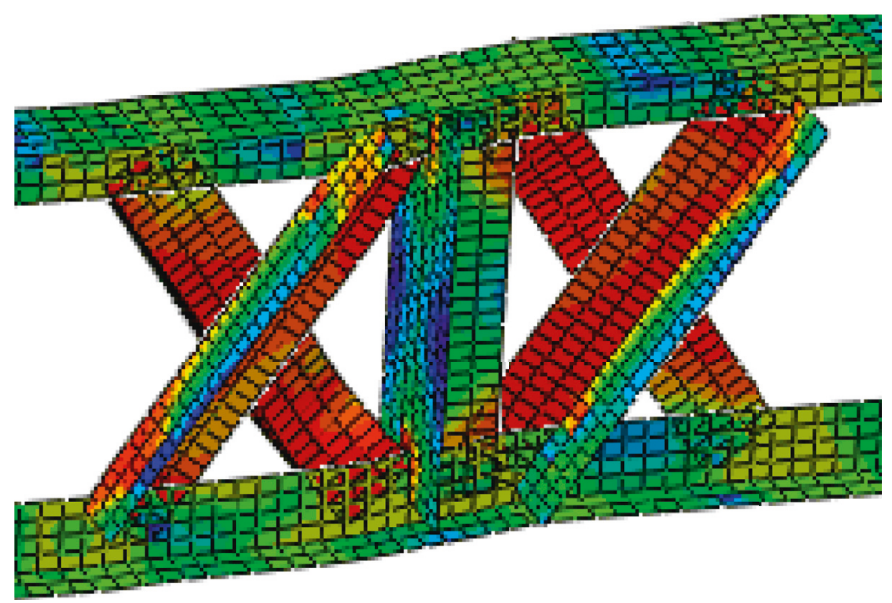

$S$, Mises

SNEG $($ fraction $=-1.0)$ (Avg.: $75 \%$ )

\begin{tabular}{|r|r|}
\hline & $+912 e+08$ \\
& $+4.511 e+08$ \\
& $+4.109 e+08$ \\
& $+3.708 e+08$ \\
& $+3.306 e+08$ \\
& $+2.905 e+08$ \\
& $+2.503 e+08$ \\
& $+2.102 e+08$ \\
& $+1.700 e+08$ \\
& $+1.299 e+08$ \\
& $+8.971 e+07$ \\
& $+4.956 e+07$ \\
& $+9.414 e+06$
\end{tabular}

(c)

FIGURE 18: Deformation and Mises stress (unit: N/m ${ }^{2}$ ) of the steel truss CBs on the 1st floor: (a) specimen WALL1; (b) specimen WALL2; (c) specimen WALL2. 
model under seismic actions. Reasonable stiffness ratio and area ratio will result in better shear wall structures with excellent deformation properties and energy dissipation capacities under earthquakes.

\section{Conclusion}

This research investigates the mechanical properties and seismic performances of steel truss CBs. The stiffness ratio and area ratio are proposed for effective evaluation and design of the steel truss CB. Numerical simulations have been conducted to understand the structural and seismic performances by employing different types of steel truss CBs. Conclusions are made as follows:

(1) Steel truss CB structures can achieve good seismic performances by the appropriate design of web and chord members. Steel members work cooperatively to satisfy strength and seismic capabilities required under seismic actions.

(2) Three major deformation patterns of steel truss CBs, with specific threshold values of stiffness ratios and area ratios, are proposed for the classification of steel truss CB structures under heavy seismic action. It is suggested that the bearing capacities and seismic energy dissipation properties of the pattern II is the best, which can be further adopted in practical design.

(3) The area ratio reflects the compatibility among steel truss members; reasonable area ratio will definitely result in good energy dissipation performances of steel truss CBs.

(4) The stiffness ratio demonstrates relative rigidities between the steel truss CBs and shear walls, as major connections between shear wall limbs; reasonable stiffness ratio can ensure an effective combination between neighboring limbs.

(5) The proposed seismic design methods based on the stiffness ratio and area ratio will provide efficient and effective seismic design of shear wall structures with steel truss CBs; it also helps to avoid compatibility problems among truss members in the structure design.

(6) The steel truss CB shear wall structure with reasonable stiffness ratio and area ratio will have good deformation properties and energy dissipation capacities; meanwhile, reasonable stiffness ratio ensures effective connections between shear wall limbs. Therefore, it is understood that the proposed steel truss CB structure will perform satisfactorily during earthquakes.

\section{Conflicts of Interest}

The authors declare that there are no conflicts of interest regarding the publication of this paper.

\section{Authors' Contributions}

Zhiheng Deng was the project leader. Changchun $\mathrm{Xu}$ is a $\mathrm{PhD}$ candidate who built the model and conducted the numerical simulation. Qiang $\mathrm{Hu}$ supervised the work. Jian Zeng helped to organize data and draw pictures. Ping Xiang analyzed the data and wrote the paper. All authors contributed to discussion of the results.

\section{Acknowledgments}

The work described in this paper was supported by grants from the National Natural Science Foundation of China (Grant no. 51268005), Guangxi Natural Science Foundation (Grant no. 2013GXNSFAA019311), and startup research funding from Central South University (Grant no. 502045006).

\section{References}

[1] B. Gong and B. M. Shahrooz, "Concrete-steel composite coupling beams. II: subassembly testing and design verification," Journal of Structural Engineering, vol. 127, no. 6, pp. 632-638, 2001.

[2] B. Gong and B. M. Shahrooz, "Concrete-steel composite coupling beams. I: component testing," Journal of Structural Engineering, vol. 127, no. 6, pp. 625-631, 2001.

[3] B. G. Gong and B. M. Shahrooz, "Steel-concrete composite coupling beams-behavior and design," Engineering Structures, vol. 23, no. 11, pp. 1480-1490, 2001.

[4] K. A. Harries, D. Mitchell, R. G. Redwood, and W. D. Cook, "Nonlinear seismic response predictions of walls coupled with steel and concrete beams," Canadian Journal of Civil Engineering, vol. 25, no. 5, pp. 803-818, 1998.

[5] K. A. Harries, D. Mitchell, W. D. Cook, and R. G. Redwood, "Seismic response of steel beams coupling concrete walls," Journal of Structural Engineering, vol. 119, no. 12, pp. 3611-3629, 1993.

[6] K. A. Harries, W. D. Cook, R. G. Redwood, and D. Mitchell, "Concrete walls coupled by ductile steel link beams," in Proceedings of the Tenth World Conference on Earthquake Engineering, vol. 1-10, pp. 3205-3210, Madrid, Spain, July 1992.

[7] W. S. Park, H. D. Yun, S. K. Hwang, B. C. Han, and I. S. Yang, "Shear strength of the connection between a steel coupling beam and a reinforced concrete shear wall in a hybrid wall system," Journal of Constructional Steel Research, vol. 61, no. 7, pp. 912-941, 2005.

[8] W. S. Park and H. D. Yun, "Seismic behaviour of steel coupling beams linking reinforced concrete shear walls," Engineering Structures, vol. 27, no. 7, pp. 1024-1039, 2005.

[9] W. S. Park and H. D. Yun, "Seismic behaviour and design of steel coupling beams in a hybrid coupled shear wall systems," Nuclear Engineering and Design, vol. 236, no. 23, pp. 2474-2484, 2006.

[10] W. S. Park and H. D. Yun, "Bearing strength of steel coupling beam connections embedded reinforced concrete shear walls," Engineering Structures, vol. 28, no. 9, pp. 1319-1334, 2006.

[11] F. J. Molina, P. Pegon, and P. Labbe, "Stiffness-displacement correlation from the RC shear wall tests of the SAFE program: derivation of a capacity line model," Advances in Materials Science and Engineering, vol. 2016, Article ID 5750672, 21 pages, 2016.

[12] J. H. Wu, Nonlinear Finite Element Analysis on Seismic Behavior for Coupled Shear Walls Structure with Steel Beam, Ph.D. thesis, Central South University, Changsha, China, 2010.

[13] Z. P. Lai, L. Z. Jiang, W. B. Zhou, and X. L. Chai, "Improved finite beam element method to analyze the natural vibration of steel-concrete composite truss beam," Shock and Vibration, vol. 2017, Article ID 5323246, 12 pages, 2017.

[14] W. B. Zhou and W. J. Yan, "Refined nonlinear finite element modelling towards ultimate bending moment calculation for 
concrete composite beams under negative moment," ThinWalled Structures, vol. 116, pp. 201-211, 2017.

[15] W. B. Zhou, L. Z. Jiang, and Z. W. Yu, "Analysis of free vibration characteristic of steel-concrete composite boxgirder considering shear lag and slip," Journal of Central South University, vol. 20, no. 9, pp. 2570-2577, 2013.

[16] L. Z. Jiang, Z. P. Lai, and W. B. Zhou, "Improved finite beam element method for analyzing the flexural natural vibration of thin-walled box girders," Advances in Mechanical Engineering, vol. 9, no. 8, Article ID 1687814017726292, 2017.

[17] W. B. Zhou, S. J. Li, Z. Huang, and L. Z. Jiang, "Distortional buckling of I-steel concrete composite beams in negative moment area," Steel and Composite Structures, vol. 20, no. 1, pp. 57-70, 2016.

[18] W. B. Zhou, L. Z. Jiang, Z. J. Liu, and X. J. Liu, "Closed-form solution for shear lag effects of steel-concrete composite box beams considering shear deformation and slip," Journal of Central South University, vol. 19, no. 10, pp. 2976-2982, 2012.

[19] W. B. Zhou, L. Z. Jiang, S. J. Li, and F. Kong, "Elastic distortional buckling analysis of I-steel concrete composite beam considering shear deformation," International Journal of Structural Stability and Dynamics, vol. 16, no. 8, Article ID 1550045, 2016.

[20] W. B. Zhou, S. J. Li, L. Z. Jiang, and Z. Huang, "Distortional buckling calculation method of steel-concrete composite box beam in negative moment area," Steel and Composite Structures, vol. 19, no. 5, pp. 1203-1219, 2015.

[21] W. B. Zhou, L. Z. Jiang, Z. Huang, and S. J. Li, "Flexural natural vibration characteristics of composite beam considering shear deformation and interface slip," Steel and Composite Structures, vol. 20, no. 5, pp. 1023-1042, 2016.

[22] W. B. Zhou, L. Z. Jiang, J. T. Kang, and M. X. Bao, "Distortional buckling analysis of steel-concrete composite girders in negative moment area," Mathematical Problems in Engineering, vol. 2014, Article ID 635617, 10 pages, 2014.

[23] W. B. Zhou, S. J. Li, L. Z. Jiang, and S. Q. Qin, "Vibration analysis of steel-concrete composite box beams considering shear lag and slip," Mathematical Problems in Engineering, vol. 2015, Article ID 601757, 8 pages, 2015.

[24] L. Z. Jiang, J. J. Qi, A. Scanlon, and L. L. Sun, "Distortional and local buckling of steel-concrete composite box-beam," Steel and Composite Structures, vol. 14, no. 3, pp. 243-265, 2013.

[25] Q. Q. Liang, B. Uy, M. A. Bradford, and H. R. Ronagh, "Strength analysis of steel-concrete composite beams in combined bending and shear," Journal of Structural Engineering, vol. 131, no. 10, pp. 1593-1600, 2005.

[26] L. Y. Zhou, Z. W. Yu, and L. Z. Jiang, "Coupled analysis of slip and deflection for continuous composite beams of steel and concrete," Advances in Structural Engineering, vol. 7, no. 3, pp. 257-269, 2004.

[27] Z. H. Deng, Q. Hu, J. Zeng, and P. Xiang, "Structural performance of steel-truss reinforced composite joints under cyclic loading," Proceedings of the Institution of Civil Engineers-Structures and Buildings, pp. 1-19, 2017.

[28] P. Xiang and H. P. Wang, "Optical fiber based sensors for distributed strain monitoring of asphalt pavements," International Journal of Pavement Engineering, pp. 1-9, 2016.

[29] P. Xiang, Z. H. Deng, Y. S. Su, H. P. Wang, and Y. F. Wan, "Experimental investigation on joints between steel reinforced concrete T-shaped column and reinforced concrete beam under bidirectional low-cyclic reversed loading," Advances in Structural Engineering, vol. 20, no. 3, pp. 446-460, 2016.
[30] H. P. Wang and P. Xiang, "Theoretical analysis on strain transfer error of FBG sensors attached on steel structures subjected to fatigue load," Strain, vol. 52, no. 6, pp. 522-530, 2016.

[31] H. P. Wang and P. Xiang, "Strain transfer analysis of optical fiber based sensors embedded in asphalt pavement structure," Measurement Science and Technology, vol. 27, no. 7, p. 075106, 2016.

[32] X. Yang, Y. Bai, F. J. Luo, X. L. Zhao, and X. H. He, "Fiberreinforced polymer composite members with adhesive bonded sleeve joints for space frame structures," Journal of Materials in Civil Engineering, vol. 29, no. 2, Article ID 04016208, 2017.

[33] G. A. Yin, F. X. Ding, H. B. Wang, Y. Bai, and X. M. Liu, "Connection performance in steel-concrete composite truss bridge structures," Journal of Bridge Engineering, vol. 22, no. 3, Article ID 04016126, 2017.

[34] X. H. He, H. X. Qin, W. S. Liu, Y. F. Chen, J. P. Zhai, and L. Yu, "Design, analysis and construction of a steel truss cable-stayed bridge for high-speed railway in China," Structural Engineering International, vol. 26, no. 4, pp. 381-388, 2016.

[35] C. K. Chen and W. Zhang, "Comparative experimental investigation on steel staggered-truss constructed with different joints in fire," Journal of Constructional Steel Research, vol. 77, pp. 43-53, 2012.

[36] C. K. Chen, D. Zhang, W. Zhang, and B. Y. Shen, "Experimental behaviors of steel staggered-truss system exposed to fire under lateral force," International Journal of Steel Structures, vol. 12, no. 1, pp. 59-70, 2012.

[37] L. Y. Zhou and G. C. He, "Experimental research on end joint of steel-concrete composite truss," Baltic Journal of Road and Bridge Engineering, vol. 7, no. 4, pp. 305-313, 2012.

[38] C. K. Chen and W. Zhang, "Experimental study of the mechanical behavior of steel staggered truss system under pool fire conditions," Thin-Walled Structures, vol. 49, no. 11, pp. 1442-1451, 2011.

[39] J. Liu, F. X. Ding, X. M. Liu, and Z. W. Yu, "Study on flexural capacity of simply supported steel-concrete composite beam," Steel and Composite Structures, vol. 21, no. 4, pp. 829-847, 2016.

[40] F. X. Ding, J. Liu, X. M. Liu, F. Q. Guo, and L. Z. Jiang, "Flexural stiffness of steel-concrete composite beam under positive moment," Steel and Composite Structures, vol. 20, no. 6, pp. 1369-1389, 2016.

[41] Y. Peng, W. Y. Deng, P. Xu, and S. G. Yao, "Study on the collision performance of a composite energy-absorbing structure for subway vehicles," Thin-Walled Structures, vol. 94, pp. 663-672, 2015.

[42] S. C. Xie, X. F. Liang, and H. Zhou, "Design and analysis of a composite energy-absorbing structure for use on railway vehicles," Proceedings of the Institution of Mechanical Engineers Part F: Journal of Rail and Rapid Transit, vol. 230, no. 3, pp. 825-839, 2016.

[43] Q. Hu, Z. H. Deng, Q. Lin, and D. X. Xu, "Analysis of failure mode and ultimate bearing capacity of steel truss coupling beam," Advances in Industrial and Civil Engineering, vol. 594-597, pp. 824-827, 2012.

[44] Q. A. Lin, Z. H. Deng, and G. X. Tang, "Experimental study on seismic behavior of full-scale new steel truss coupling beams," Advances in Structures, vol. 163-167, pp. 2041-2046, 2011.

[45] Z. H. Deng, Q. Hu, Q. Lin, and D. X. Xu, "Experimental research of steel truss coupling beam on seismic behavior and energy dissipation mechanism," in Proceedings of ISISS '2009: Innovation \& Sustainability of Structures, vol. 1-2, pp. 15001505, Guangzhou, China, November 2009.

[46] Z. H. Deng, G. X. Tang, P. Xiang, and X. Y. Wang, "Experimental study on joints of steel reinforced concrete 
T-shaped column under to direction low-cyclic reversed loading," in Proceedings of the Tenth International Symposium on Structural Engineering for Young Experts, vol. 1-2, pp. 895-900, Changsha, China, October 2008.

[47] H. F. Yang, Z. H. Deng, Y. H. Qin, and L. S. Lv, "A study on the bond behavior of corroded reinforced concrete containing recycled aggregates," Advances in Materials Science and Engineering, vol. 2015, Article ID 249301, 9 pages, 2015.

[48] Z. H. Deng, Q. Lin, Q. Hu, Z. M. Pan, and D. X. Xu, "Test for seismic behaviors of new steel truss coupling beams," Journal of Vibration and Shock, vol. 31, pp. 76-81, 2004.

[49] Q. Lin, Z. H. Deng, and Q. Z. Liu, "Experimental study and nonlinear finite element analysis on the seismic performance of full-scale steel truss coupling beams," Engineering $\mathrm{Me}$ chanics, vol. 29, pp. 256-263, 2012.

[50] Q. Hu, T. J. Liao, and Z. H. Deng, "Cyclic loading experiment on seismic behavior of shear wall with steel truss coupling beam," Journal of Earthquake Engineering and Engineering Vibration, vol. 34, pp. 1-10, 2014.

[51] K. Sugiura, G. C. Lee, E. Watanabe, and K. C. Chang, "Instability of steel short column under cyclic loadings," Stability and Ductility of Steel Structures under Cyclic Loading, pp. 15-23, CRC Press, Osaka, Japan, 1992.

[52] K. Sugiura, K. C. Chang, and G. C. Lee, "Evaluation of lowcycle fatigue-strength of structural metals," Journal of Engineering Mechanics, vol. 117, no. 10, pp. 2373-2383, 1991.

[53] K. Sugiura, G. C. Lee, and K. C. Chang, "Endochronic theory for structural-steel under nonproportional loading," Journal of Engineering Mechanics, vol. 113, no. 12, pp. 1901-1917, 1987.

[54] E. Watanabe, K. Sugiura, M. Kanou, M. Takao, and S. Emi, "Hysteretic behavior of thin tubular beam-columns with round corners," Journal of Constructional Steel Research, vol. 18 , no. 1 , pp. 55-69, 1991.

[55] E. Watanabe, K. Sugiura, and W. O. Oyawa, "Elasto-plastic instability of steel compression tubular members subjected to cyclically applied bi-directional horizontal loads," ThinWalled Structures, pp. 809-816, 1998.

[56] L. S. He, M. Kurata, and M. Nakashima, "Condition assessment of steel shear walls with tapered links under various loadings," Earthquakes and Structures, vol. 9, no. 4, pp. 767-788, 2015.

[57] S. Gwon, M. Shin, B. Pimentel, and D. Lee, "Nonlinear modeling parameters of RC coupling beams in a coupled wall system," Earthquakes and Structures, vol. 7, no. 5, pp. 817-842, 2014.

[58] GB50010-2002, Code for Design of Concrete Structures, China Architecture and Building Press, Beijing, China, 2002 (in Chinese). 


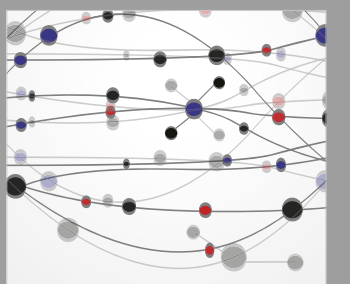

The Scientific World Journal
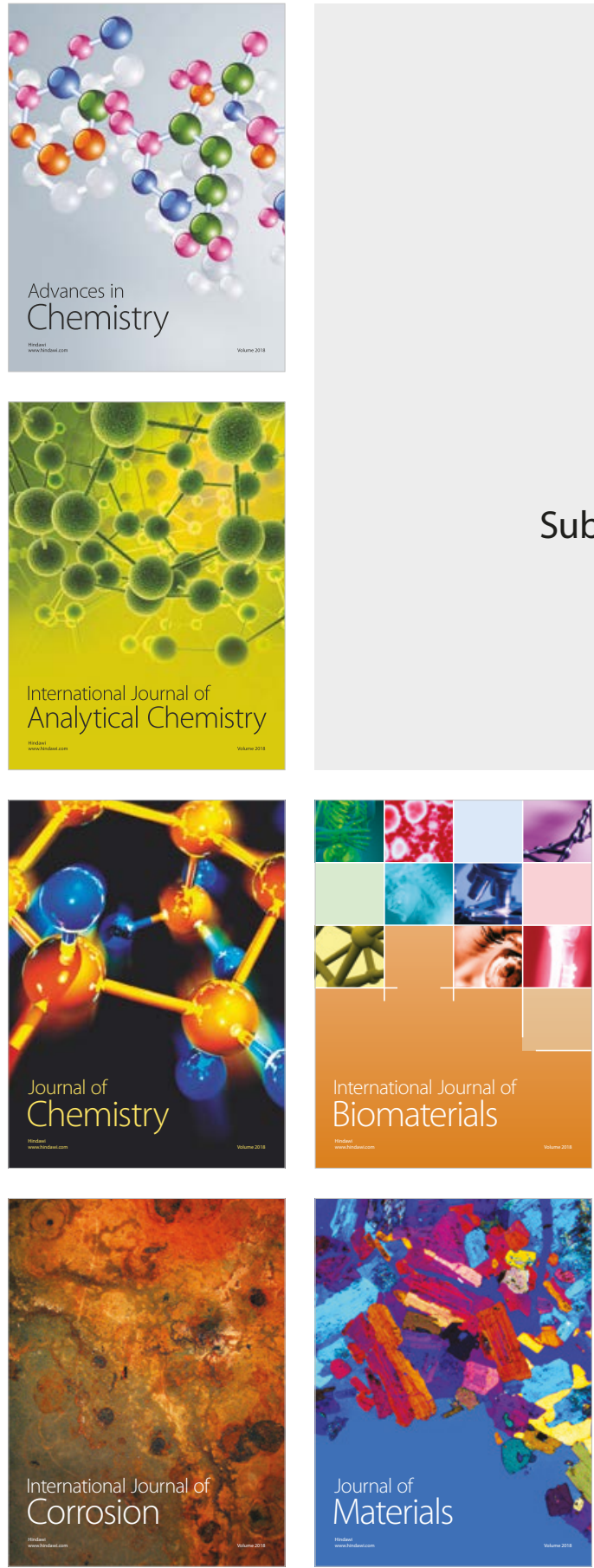

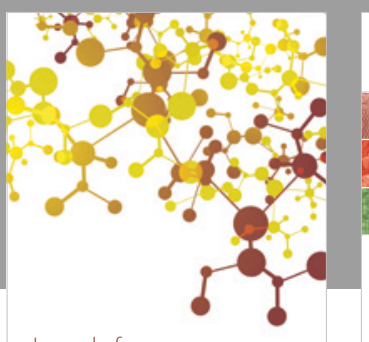

Journal of

Applied Chemistry
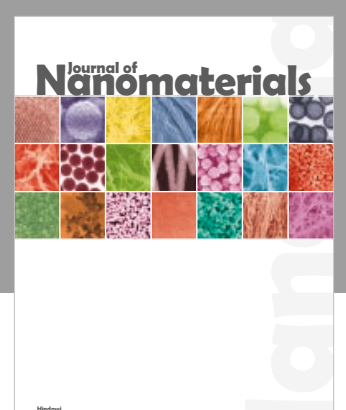

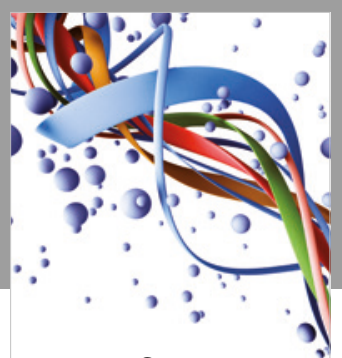

Scientifica

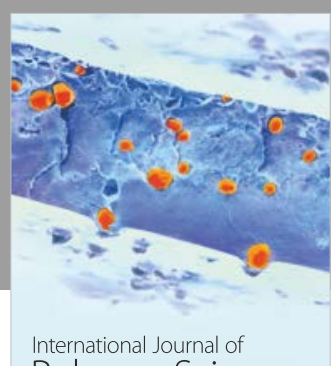

Polymer Science

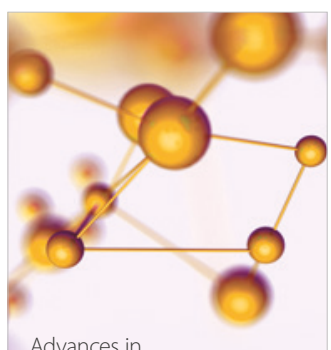

Physical Chemistry
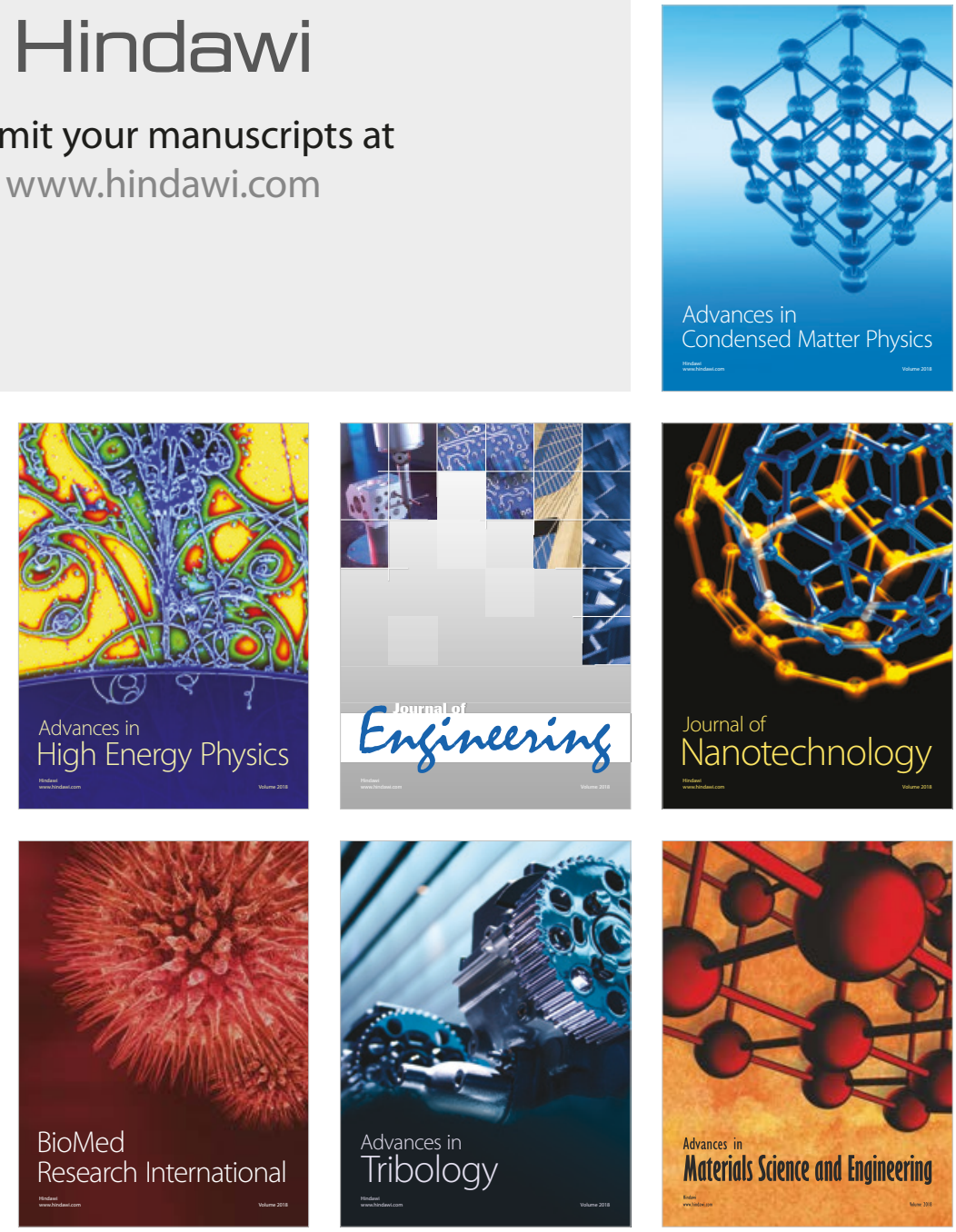